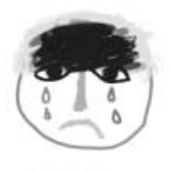

Under the auspices of the

这么

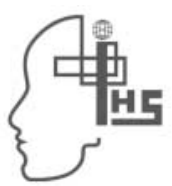

International Headache Society

\title{
Abstracts of the VI International Congress on Headache in Children and Adolescents
}

\author{
Vienna, Austria \\ April 21-25, 2004
}

\section{Disclaimer}

These abstracts have been produced using author-supplied copy. Editing has been restricted to some corrections of spelling and style where appropriate. No responsibility is assumed for any claims, instructions, methods or drug dosages contained in the abstracts: it is recommended that these are verified independently. 


\section{TEACHING COURSE}

\section{TC-1 \\ PATHOPHYSIOLOGY OF MIGRAINE}

\section{P.J. Goadsby}

Headache Group, Institute of Neurology, Queen Square, London, UK; e-mail: peterg@ion.ucl.ac.uk

Migraine is an episodic disorder of sensory processing that results in head pain, usually, of a throbbing nature, and sensitivity to light, sound, sometimes smells, and often to head movement. There are more similarities than differences in childhood and adult migraine if they are viewed as disorders of sensory modulation [1]. Functional brain imaging has been enormously helpful in beginning to unravel the likely loci of the dysfunctional nuclei in migraine. Activation in the dorsal midbrain and dorsolateral pons has been observed with PET in both episodic and chronic migraine [2-4]. It has been shown that midbrain regions can modify trigeminovascular nociceptive afferent activity [5], and most recently that this modification may have implications for understanding the mechanism of action of triptans [6], serotonin $5-\mathrm{HT}_{1 \mathrm{~B} / 1 \mathrm{D}}$ receptor agonists, that are so effective in acute migraine. Brain imaging has identified the dorsolateral pons, which contains the nucleus locus coeruleus, the major noradrenergic influence on cortical sensory processing that certainly has important trigeminal inhibitory effects in experimental settings. Another important aspect of brain function that will require understanding is the extent to which thalamic modulation plays a role in migraine. It is clear that neurons in ventroposteromedial (VPM) thalalmus receive input from trigeminovascular neurons [7]. These neurons are modulated by GABAergic mechanisms [8], and this offers entirely new target for intervention, perhaps a target for considering the effects of preventive medications.

References

1. Goadsby PJ (2003) Migraine pathophysiology: the brainstem governs the cortex. Cephalalgia 23:565-566

2. Weiller C, May A, Limmroth V, Juptner M, Kaube H, Schayck RV et al (1995) Brain stem activation in spontaneous human migraine attacks. Nat Med 1:658-660

3. Bahra A, Matharu MS, Buchel C, Frackowiak RSJ, Goadsby PJ (2001) Brainstem activation specific to migraine headache. Lancet 357:1016-1017

4. Matharu MS, Bartsch T, Ward N, Frackowiak RSJ, Weiner RL, Goadsby PJ (2004) Central neuromodulation in chronic migraine patients with suboccipital stimulators: a PET study. Brain 127:220-230

5. Knight YE, Bartsch T, Kaube H, Goadsby PJ (2002) P/Q-type calcium channel blockade in the PAG facilitates trigeminal nociception: a functional genetic link for migraine? J Neurosci 22:1-6

6. Bartsch T, Knight YE, Goadsby PJ (2003) The 5-HT $1 \mathrm{~B} / 1 \mathrm{D}$ receptor agonist naratriptan microinjected into the periaqueductal grey selectively inhibits meningeal nociception. Cephalalgia 23:650

7.Zagami AS, Lambert GA (1990) Stimulation of cranial vessels excites nociceptive neurones in several thalamic nuclei of the cat. Exp Brain Res 81:552-566

8. Shields KG, Kaube H, Goadsby PJ (2003) GABA receptors modulate trigeminovascular nociceptive transmission in the ventroposteromedial (VPM) thalamic nucleus of the rat. Cephalalgia 23:728

\section{TC-2}

\section{CLINICAL FEATURES AND DIAGNOSIS OF MIGRAINE}

C.. Wöber-Bingöl

Headache Unit, Dept. of Neuropsychiatry of Childhood and Adolescence, Medical University of Vienna, Vienna, Austria; e-mail: yasar.woeber-bingoel@univie.ac.at

The prevalence of migraine in children and adolescents ranges between $3 \%$ and $12 \%$ and increases with age. Migraine causes a considerable impact on the quality of life of children and adolescents due to unpredictable headache attacks associated with further symptoms such as nausea, vomiting, photophobia and phonophobia. Often the children are forced to stop playing or learning. As a consequence, (psycho)social functioning may be impaired in various areas including family, peer group, friends, leisure time activities, and productivity at school. The clinical features of migraine in young patients differ from those in adults. Most strikingly, the duration of the attacks is shorter and the location is usually median or bilateral in the frontal region. Furthermore, children report less often pulsating pain, photophobia and phonophobia, and more often aggravation by physical activity compared to adults. In addition, it is important to realize that the clinical features change in a considerable number of patients which may cause a shift from migraine to tension-type headache. Establishing the diagnosis of migraine requires a detailled history with the patient and the mother or father. Based on the history and the clinical examination the physician must decide whether additional examinations are required or not. Among the latter cranial magnetic resonance imaging and computerized tomography, respectively, are most important. In addition, it is essential to ask for the patient's lifestyle and for possible precipitating factors. Finally, all patients should keep a headache diary for 4 to 8 weeks. The headache diary is required for establishing the definite diagnosis as well as for providing adequate treatment.

\section{TC-3 ABDOMINAL MIGRAINE AND OTHER PERIODIC SYNDROMES \\ D.N.K. Symon}

University Hospital of Hartlepool, Hartlepool, UK; e-mail: david.symon@nth.nhs.uk

Abdominal migraine is an idiopathic disorder seen mainly in children. There are recurrent episodes of midline abdominal pain with attacks lasting 1-72 hours and complete normality between episodes. Pain is of moderate to severe intensity and is felt in the midline of the abdomen. Attacks of pain are usually accompanied by anorexia and nausea and about half of patients will vomit with at least some attacks. Pallor is commonly noted during the attacks although some patients may appear flushed. The attacks resolve spontaneously. Cyclical Vomiting Syndrome is a condition of recurrent episodic attacks of vomiting and intense nausea. Episodes are similar in time of onset, duration and symptomatology specific for each patient. The principal feature of the condition is recurrent discreet episodes of vomiting lasting hours or days with frequent retching. There is a high frequency of vomiting at the peak of the attack with vomiting every 10-15 minutes. Average attack duration is 24 hours but is considerably longer in some patients. Attacks are self-limited and shortly afterwards the child is likely to be completely well and demanding food. Between attacks the patient is completely well. Benign paroxysmal vertigo of childhood is characterised by recurrent brief episodic attacks of vertigo occurring without warning and resolving spontaneously. All these conditions are now included within the migraine section of the IHS Classification of Headache Disorders.

\section{TC-4 \\ TREATMENT OF MIGRAINE}

\section{Hämäläinen}

Hospital for Children and Adolescents, University of Helsinki, Finland; e-mail: mirja.hamalainen@hus.fi

A correct diagnosis is a prerequisite for adequate interventions. Therefore a careful history and a complete physical examination are mandatory before any further steps. Non-drug treatment includes regular meals and sufficient sleep. It may be useful to avoid recognized trigger factors. Children should be allowed to sleep away a migraine attack; this may be enough in short-lasting attacks. However, in severe, 
disabling and longer attacks, symptomatic drug treatment is often required. Drugs should be given at the onset of a migraine attack, followed by rest in a quiet place. Paracetamol $(15 \mathrm{mg} / \mathrm{kg})$ and ibuprofen $(10 \mathrm{mg} / \mathrm{kg})$ are both effective as first-line attack treatments for migraine. Sumatriptan nasal spray is the only triptan registered for children aged 12 years or more. Prophylactic drug treatments of migraine have not proved very efficacious in children, and no single drug is superior when its potential side effects are considered. However, betablockers, such as propranolol, and amitriptyline have been used with success. As compared to drug treatments, biobehavioral treatments have shown equal or better efficacy in school-aged children. Biobehavioral treatments can be used together with paracetamol, ibuprofen and sumatriptan nasal spray. Limited availability of biobehavioral treatments restricts their use in the treatment of migraine in children.

\section{TC-5 PATHOPHYSIOLOGY OF TENSION-TYPE HEADACHE}

\section{J. Schoenen}

Neurology and Neuroanatomy, University of Liège, Headache Unit CHR Citadelle, Liège, Belgium; e-mail: jschoenen@ulg.ac.be

TTH is the most common form of headache, but receives much less attention from health authorities, clinical researchers or industrial pharmacologists than migraine. This may be due to the fact that most subjects with TTH do never consult a doctor and treat themselves, if necessary, with over-the-counter (OTC) analgesics. However, frequent and chronic TTH constitute a major health problem with an enormous socioeconomic impact. The exact causes of TTH are still unknown. Both peripheral myofascial mechanisms and central dysregulation of pain processing structures have been found, but their relative weight in TTH pathogenesis varies with headache frequency and between patients. There are no ancillary investigations that are diagnostic for this form of headache and the disease definition relies therefore exclusively on symptomatology, which, as mentioned, is not as distinct as for migraine. Because of this lack of disease-specific features, a number of secondary headaches can present as TTH. Despite the meagre scientific foundations regarding both mechanisms and treatments of TTH, it is not impossible to manage these patients with some success, even though there has been no major therapeutic breakthrough in recent years.

\section{TC-6 \\ CLINICAL FEATURES AND TREATMENT OF TENSION-TYPE HEADACHE}

V. Guidetti, F. Galli

Department of Child and Adolescent Neurology and Psychiatry, University “La Sapienza”, Rome, Italy; e-mail: v.guidetti@iol.it

Tension-type headache (TTH) in children and adolescents is the most common type of headahe both in adults and children or adolescents. However, little we know on etiology, diagnosis, pathophysiology and prognosis of TTH. The diagnosis of TTH in children has to take into account age-related characteristics of symptoms: mixed migraine and tension features are common in headache sub-types with onset in the youngers. Follow-up studies showed the trend of both migraine and TTH to change each other (Dooley and Bagnell, 1995; Guidetti and Galli, 1998): it opens to several questions on the likely continuum of the two headache sub-types. Episodic TTH may also develop into chronic TTH: factors involved in the chronicization (drug abuse? Psychiatric disorders?) need further studies for pathophysiological and therapeutic implications. Muscolar stress, oromandibular dysfunction, depression, psychosocial factors and drug overuse had been involved as causative factors for TTH in adults. For children the association of TTH and these factors has not been completely studied and understood: however it seems possible (Karwautz et al.,1999; Anttila et al., 2002) and seemingly different from adults.

\section{TC-7}

\section{DAILY HEADACHES}

\section{Farkas}

University Children's Hospital, Semmelweis University, Budapest, Hungary; e-mail: farkas@gyer1.sote.hu

The second edition of the The International Classification of Headache Disorders are aetiological for the secondary headaches and symptombased for primary headaches. The electrophysiology, genetics, etc of headaches may simply prove to be so complex that, in daily practice and to some extent in research, we shall continue with clinically-defined diagnoses by using precise, "explicit" diagnostic criteria. Chronic daily headache $(\mathrm{CDH})$ is not a definitive diagnosis, it is a clinical syndrome that invites investigation and diagnostic refinement. It is the most common headache seen in headache specialty clinics for children and adolescents, and has enormous medical and socio-economic ramifications. $\mathrm{CDH}$ in children is an umbrella term for disorders with similar features and multiple underlying causes and may be a useful clinical term. All the primary headaches presenting with chronic temporal pattern may be grouped. Different disorders may have similar, even indistinguishable clinical pictures. Cluster headache and chronic paroxysmal hemicrania $(\mathrm{CPH})$ are good example. Unless indomethacin response is tested it may be impossible to differentiate them clinically. Recently important changes have been made in the major group of daily headaches by introducing the term chronic migraine as a new diagnosis for those rare patients who fulfil the diagnostic criteria for migraine on 15 or more headache days a month without overusing medication. Some new entities such probable chronic migraine, hemicrania continua have also been added and described. The second edition of classification recognises new dailypersistent headache (NDPH) as a separate entity from chronic tensiontype headache. Recently it is a fact that the evolution of primary headaches syndromes cannot be predicted. It is an important task for the future also for pediatricians to provide prognostic factors and other characteristics by bigger studies that may classify subtypes of primary headaches according to evolutionary patterns. In secondary daily headaches the causal link between the underlying disorder and the headache is in most cases well-established and to strengthen it the terminology "attributed to" is used. The recent classification gives more headache characteristics in secondary headaches whenever possible, however these characteristics itself for most secondary headaches are poorly described in the scientific literature, especially in children. On the other hand the format for the diagnosis of secondary headaches is now standardised. According to diagnostic criteria headache occurs in close temporal relation to another disorder known from the good scientific studies to be able to cause headache, furtheron headache is greatly reduced or resolves within a time-limit after cure or spontaneous remission or removal of the presumed cause. Secondary headaches persisting after this time-limit have often be observed but most have not been of scientifically-proven aetilogy. Such cases are summerized in the appendix of recent classification as chronic headache attributed to (a specified disorder). Further clinical characterisation according to types, subtypes and pathophysiologicfal reserach comparing daily headache entities is stimulated in order to select rigth treatment and to prevent medication-overuse headache.

\section{TC-8}

\section{MIGRAINE AND HEADACHES IN CHILDHOOD AND ADO- LESCENCE: BEHAVIOURAL ASPECTS}

W.-D. Gerber

Center of Nervous Disease, University of Kiel, Germany; e-mail: gerber@med-psych.uni-kiel.de

Headaches in children and adolescents belong to most frequent chronic diseases in the childhood and the adolescence. More than $15 \%$ of the children with the age of 6 to 16 years suffer from chronic headaches mostly from migraine and tension-type headaches. The etiology of these kinds of headaches is not really well known. From a retrospective sight 
children with headaches often have shown specific behavioural patterns from the beginning of their life. Abnormal behavioural patterns like perfectionism, hypersensitivity a.o. often have been described to be specific psychological characteristics in migraine patients which possibly seems to be aquired in consequence of the migraine disease. We propose that behavioral abnormalities may be the result of a genetically determined cortical hypersensitivity, possibly associated with learning processes. New neuro(psycho)physiological data seem to support the notion that migraine is a brain stem information processing dysfunction that is characterized by cortical hypersensitivity and reduced habituation to stimuli. The cortical activity reflects a (time) periodicity and may be related to endogenous or exogenous factors. Based on the currrent understanding of behavioural and neurophysiological aspects of migraine, we assume a two-process model of migraine aetiology: (1) a genetically determined hyperactivity of the central monoaminergic (catecholaminergic) system which could be possibly modulated by learning processes and (2) a homeostatic (counter) regulation and mobilization of reduced (mitochondrial) energy reserve. We further hypothesize that the catecholaminergic hyperactivity represents a possibly learned SelfReinforcement-System (SRS). The chronification of migraine could be the result of operant conditioning processes which are related to both, biological and behavioral patterns. The results indicate to new behavioral procedures in the treatment of migraine which will be described.

\section{TC-9 \\ SYMPTOMATIC HEADACHES: WHEN TO WORRY, WHAT TO DO}

C. Wöber

Headache Unit, Department of Neuropsychiatry of Childhood and Adolescence, Medical University of Vienna, Austria; e-mail: christian.woeber@meduniwien.ac.at

Headache is a frequent symptom among children and adolescents. in the general population. More than $80 \%$ of the children experienced headache at some time in their lives. Almost all headaches encountered in general/family practice are subtypes of migraine, tension-type headache and chronic daily headache or related to common viral infections. In a pediatric emergency department, less than $7 \%$ of 288 patients presenting with headache had a serious disorder including 15 patients with viral meningitis. Among more than 430 patients of a headache center, less than $6 \%$ had symptomatic headache including two patients with a serious disease. Patients with brain tumors complain of headache in more than $60 \%$, but headache is usually strongly associated with other symptoms and signs of an intracranial space occupying lesion and headache is rarely the only presenting symptom of a brain tumor. Considering the large number of benign headaches it is essential that the physician screens adequately for possible (but very rare) sinister or worrisome headaches arising as a side effect of serious and life-threatening illnesses, such as meningitis and other infections, intracranial haemorrhages, primary and secondary brain tumours, cerebral abscesses, or hydrocephalus. Recently, a new algorithm for the diagnosis of sinister headache was published. This algorithm incorporates the patient's age, headache onset and acuteness and presenting symptoms. The presence of one or more of the following features indicates a possibly sinister headache: (1) first occurrence of headache at a very young age, (2) new onset headache, (3) headache with very acute onset, and (4) headache associated with (a) atypical or isolated symptoms, (b) conditions such as head injury, infection or hypertension, (c) prolonged neurological deficits and (d) abnormal neurological exam. In the presentation, this algorithm as well as the emergency management of sinister headaches will be discussed in details.

Suggested readings

- Dowson AJ, Sender J, Lipscombe S, Cady RK, Tepper SJ, Smith R, Smith TR, Taylor FR, Boudreau GP, van Duijn NP, Poole AC, Baos V, Wober C (2003) Establishing principles for migraine management in primary care. Int J Clin Pract 57(6):493-507
- Wöber-Bingöl Ç, Wöber Ch, Karwautz A, Vesely Ch, WagnerEnnsgraber Ch, Amminger GP, Zebenholzer K, Geldner J, Baischer W, Schuch B (1995) Diagnosis of headache in childhood and adolescence: a study in 437 patients. Cephalalgia 15:13-21

\section{SPECIAL LECTURES}

\section{S-1 IHS President's LeCtURE METHODOLOGY OF CONTROLLED CLINICAL TRIALS. WHAT ARE THE DIFFERENCES BETWEEN CHILDREN AND ADULTS? \\ P. Tfelt-Hansen \\ Department of Neurology, Glostrup Hospital, Glostrup, Denmark; e- mail:tfelt@inet.uni2.dk}

\section{S-2 Vahlquist-Bille-Lecture TOWARDS 50 YEARS OF EPIDEMIOLOGY IN CHILDHOOD HEADACHE \\ M. Sillanpaa}

Departments of Child Neurology and Public Health, University of Turku,Turku, Finland; e-mail: matti.sillanpaa@utu.fi

Research into the epidemiology of childhood headache was pioneered by Bo Bille in Uppsala, Sweden in the late 1950s under the auspices of professor Bo Vahlquist, who developed one widely used set of criteria for paediatric migraine. Bille's monumental study and analysis of 9000 schoolchildren, his doctoral thesis, constituted the basis of subsequent epidemiological studies on the topic. Applying the Vahlquist criteria for migraine, he demonstrated an increase in the occurrence of migraine from $1.4 \%$ to $5.3 \%$ and overall headache from $39 \%$ to $75 \%$, respectively, in schoolchildren aged $7-15$ years. The male majority in the occurrence turned to female majority at age 10-12 years. Similar results have been reported in subsequent studies within and outside Nordic countries. A subgroup of 73 children with ,,pronounced migraine“ were prospectively followed for 40 years. Approx. $25 \%$ hade become attack-free up to age 25 years, but about $50 \%$ had still migraine at age 50 years. So, the roots of adult headache are often in childhood. The outcome was better among boys than in girls. A Finnish long-term prospective study could confirm Bille's main results. In addition to valuable epidemiological data, Bille's fundamental research was a starting signal for further studies on the occurrence, causes and consequences of paediatric headache. The future epidemiological research will further elucidate the natural course of headache from childhood to adulthood and its medical, social and societal effects.

\section{INVITED SPEAKERS}

\section{L-1} THE IHS-CLASSIFICATION 2004. WHAT ARE THE NEWS?

\section{R.H. Jensen}

Danish Headache Center, Department of Neurology, University of Copenhagen, Glostrup Hospital, Glostrup, Denmark; e-mail: rj@dadlnet.dk

The first edition of The International Headache Classification was virtually immediately accepted throughout the world for scientific purposes, especially the big wave of triptan drugs studies were all done in patients diagnosed according to the international headache classification. Slowly, but surely the principles of the classification have also altered clinical practice. The second edition has not changed the major 
principles of the classification and diagnosis of primary headache disorders. A number of small but important changes have been made in the light of new evidence. The scientific evidence for major changes of the diagnostic criteria of headache in children and adolescents was scarce and the diagnostic criteria for migraine are only changed to include 2 comments describing the shorter duration of migraine attacks in children and the specific problems regarding this group. Furthermore, a specific subgroup for Childhood Periodic Syndromes that are commonly precursors of migraine are also defined. There are no age-specific changes in the revised diagnostic criteria for other primary and secondary headache disorders. The revised version of the IHS-classification will be presented and discussed.

\section{L-2 \\ DIAGNOSTIC VALUE OF THE IHS CRITERIA IN CHILDREN AND ADOLESCENTS WITH MIGRAINE AND TENSION-TYPE HEADACHE \\ A. Özge \\ Mersin University, School of Medicine, Mersin, Turkey; e-mail: aozge@mersin.edu.tr}

Headache is a common symptom in paediatric practice. Childhood headache, especially migraine has specific characteristics other than adult migraine. There are some epidemiological studies about the reliability of the IHS criteria for the diagnosis of TTH and the demographic characteristics of the children with TTH. While the development of the IHS criteria is a vital step forward in headache diagnosis, its contribution is in the area of criterion variance. The IHS does little to address the issues of information and interpretation variance. Diagnostic agreement among independent clinicians is often surprisingly poor and in the field of headache has not been adequately studied. The headache diagnosis in children is based on an overall interpretation of clinical symptoms. Now and future work should focus on alternative case definitions based on behaviour rather than symptoms (i.e., going to a dark room, squinting, turning off the lights instead of photophobia). Exploring additional or alternative diagnostic features (e.g. pallor, abdominal pain, sensitivity to odours, menstrual exacerbation) may be helpful. The objectives of our study were to estimate the prevalence of recurrent headaches in schoolchildren (ranging from $2^{\text {nd }}$ to $5^{\text {th }}$ degrees) in Mersin city of Turkey, and to determine the sensitivity, specificity, positive predictive value and positive likelihood ratio of the diagnostic headache characteristics in children with migraine and Tension Type Headache (TTH) using neurologist's diagnosis as the gold standard. In order to validate study procedure, we performed a preliminary study with 110 children. The ratios of sensitivity, specificity, positive predictive value (PPV) and positive likelihood ratio (PLR) were calculated using the neurologist diagnosis as a reference test. These ratios were $94.4 \%, 55.3 \%$ and $67.1 \%$, respectively. The stratified sample of this study was composed of 5562 children. The prevalence of recurrent headache was $49.2 \%$ (2739 of 5562) and the prevalence of current headache was $31.3 \%$ ( 859 of 2739). TTH was more common than migraine $(24.7 \%$ versus $10.4 \%)$. The mean duration of headache was found to be significantly longer in children with migraine (the average duration was 2.6 hours, ranged from 1 hour to 48 hours) than children with TTH (the average duration was 1.9 hours, ranged from 30 minutes to 72 hours) in our study. Based on our findings and prior reports we also support the suggestion to decrease the criterion on the minimal duration of pain to one hour for migraine headaches in children. For the IHS-based diagnosis of migraine, nausea and vomiting have poor sensitivity and high specificity in this model. However, having the at least one associated symptom has poor sensitivity and specificity for the IHS-based diagnosis of TTH in schoolchildren. The most sensitive headache characteristic for migraine was "severity of pain" $(86.6 \%)$ and the most sensitive definitive symptom is "duration of headache" (95.3\%) in children with TTH. Logistic regression analysis revealed that pulsating quality of headache (ExpB: 4.21), aggravation with walking stairs (ExpB:1.45), not being able to watch television during headache attacks (ExpB:3.73), having nausea (ExpB:2.46) or vomiting (ExpB:7.16) associated with headache attacks and unilateral location of headache (ExpB:22.62) had significant effect on migraine of schoolchildren. On the other hand, headache frequency (ExpB:1.05) and recent minor head trauma (ExpB: 1.68) had an important effect on TTH attacks of schoolchildren. It was concluded that IHSbased symptom definition criteria are highly beneficial in diagnosis of childhood headache, if used together with detailed clinical assessment.

\section{L-3 \\ GENETICS OF MIGRAINE}

\section{P. Montagna}

Department of Neurological Sciences, University of Bologna Medical School, Bologna, Italy; e-mail: pmontagna@neuro.unibo.it

Migraine is currently considered a complex disease with multifactorial genetic determination. The relative disease risk is increased 1.9 times for first degree relatives of probands with migraine without aura, and four times for relatives of probands with migraine with aura. Symptoms of migraine begin at an earlier age in children with higher number of affected relatives, e.g. with a heavier genetic load. Migraine before 20 years is associated with a positive family history, especially along the maternal line, of migraine in the mother predicting children's preschool headache. Studies in twins demonstrate that concordance rates for migraine are consistently higher among mono-zygotic than di-zygotic twins. Several linkage, genome wide screens and association studies with candidate genes have been performed in migraine, but the results of many studies are still considered as preliminary and in need of confirmation. Thus, linkage has been found with the Insulin Receptor Gene (INSR) at 19p13.3/2; with Xq24-28; with 4q24 for migraine with aura in a genome wide screen of Finnish families; with 1q31; 16p12; 14q21.2-22.3 for migraine without aura; and with 11q24. Association studies have been performed with serotonin and dopamine receptor genes, prothrombotic/vascular risk genetic factors, and mitochondrial DNA. Only for Familial Hemiplegic Migraine, a variety of migraine with aura conforming to an autosomal dominant type of mendelian transmission, are the genes involved known: FHM1 is due to mutations in the CACNA1A gene, coding for a neural calcium channel; mutations in the ATP1A2 gene, coding for an alpha 2 subunit of the $\mathrm{Na} / \mathrm{K}$ ATPase account for FHM2. The relevance of FHM as a genetic model for the more common types of migraine with and without aura remains however controversial.

\section{L-4 ALTERNATING HEMIPLEGIA IN CHILDHOOD: A GENETICALLY HETEROGENEOUS MIGRAINE RELATED DISORDER?}

\section{T. Schyns}

European Network for Research on Alternating Hemiplegia (ENRAH); e-mail: tl.ps@gmx.net

Alternating Hemiplegia in Childhood (AHC) is a rare condition, which is symptomatically ascribed and diagnosed by its striking neurological features: infantile onset of migraines, recurrent hemiplegic attacks involving alternatively each side of the body and other paroxysmal phenomenon. The cause(s) and the pathophysioligy of the disease are yet unclear. Here, we will discuss approaches to seek for the causative genetic mechanisms in AHC. The occurrence of familial cases with AHC symptoms suggest an autosomal dominant mode of inheritance of the disease. Nevertheless, it is very likely that the similar clinical phenotypes, however indistinguishable, are resulting from altogether different pathologies. The ongoing efforts in the USA and Europe to screen candidate genes for AHC on the ground of its clinical similarity to other paroxysmal periodical diseases, will be reviewed in the light of the recent advances in the filed of genetics of familial hemiplegic migraine (FHM).Further, the recently founded European Network for 
research on $\mathrm{AHC}$ of patients organisations, clinicians, scientists and industry will be presented. Attention will be given to the current activities of the network to establish a database of clinical records on AHC and to facilitate and promote the research with the ultimate goal to deliver proper diagnostic tools and effective treatment.

\section{L-5 MEDICATION IS IMPORTANT}

P. Winner

Palm Beach Headache Ctr, West Palm Beach, FL, USA; e-mail: pwinner777@aol.com

In the pediatric population, migraines are primarily an episodic syndrome that often renders the individual incapacitated, with personal, social and possibly medical consequences if not controlled effectively The rational treatment of migraines begins with educating the patient and parents as active participants in their treatment. In this population, nonpharmacologic modalities need to be utilized but when partially or totally ineffective, appropriate medication needs to be administered. Episodic headaches often respond well to acute medications. When the frequency intensifies, preventive therapy needs to be entertained. All management strategies need to be challenged, both due to the underlying variability of headaches in this age group, as well as the changing opportunities available for medical treatment.

\section{L-6 NON-PHARMACOLOGICAL TREATMENT IS IMPORTANT \\ F. Andrasik}

Institute for Human and Machine Cognition, University of West Florida, Pensacola, FL, USA; e-mail: fandrasik@ihmc.us

Beginning with the first publication of a nonpharmacological treatment for pediatric headache nearly 30 years ago (Diamond and Franklin, 1975), evidence supporting the value of this type of approach has been steadily mounting. Evidence-based reviews as well as meta-analytic or quantitative reviews document the efficacy of a number of relaxationbased (progressive muscle relaxation and biofeedback) and cognitivebased therapies. These reviews, as well as direct experimental comparisons, indicate that such approaches are comparable to pharmacological treatments. Non-pharmacological treatments have a number of potential advantages, as well. Among these are the minimal occurrence of adverse side effects; decreased attrition from and adherence to treatment; acquisition of actual skills that can directly improve coping abilities, which in turn can enhance confidence and self-esteem and minimize negative affect; elimination of parent concern about potential adverse effects of certain medications during critical growth periods. These approaches fit with a growing desire of patients to seek treatment alternatives, either as a replacement for or an addition to their care.

\section{L-7 \\ COMPLEMENTARY TREATMENTS ARE USEFUL}

\section{R. Pothmann}

Pediatric Pain Center, Hamburg, Germany; e-mail:pothmann@aol.com

The most adequate treatment especially in young children is a therapy with less side effects. For example in acute headache cold pack or local massage with peppermint oil will help a lot in younger children. A lot of them will finally fall into sleep as the most striking acute coping element. Additive prophylactic treatment is given in frequent and longlasting, severe and complicated headache and migraines. New controlled data in adults and open label data in children have shown that phytopharmacological treatment like butterbur root extract Petadolex or a complex homeopathic solution like Antimigren has convincing effects. Not only in case of therapeutic resistance one could go the diet-way.Evidence is given by controlled investigations showing that especially severe migraines with comorbidity of allergies, but as well tension-type headaches are responding to trigger reduced nutrion within a short period of only 2 months without any side effects. In addition eating-behaviour could be a main instrument in influencing the psycho-social conditions of the children's families. Even acupuncture is a serious and effective option for school children in case of pharmacological side effects, informed consent as a predisposition. Complementary headache treatment in children and adolescents is a basic option and should be preferred because lower of side effects before high dose chemical drugs will be tried.

\section{L-8} COMPLEMENTARY TREATMENTS ARE NOT USEFUL

\section{Wöber}

Headache Unit, Department of Neuropsychiatry of Childhood and Adolescence, Medical University of Vienna, Vienna, Austria; e-mail: christian.woeber@meduniwien.ac.at

Complementary and alternative medicine (CAM) is defined as a group of diverse medical and health care systems, practices, and products that are not presently considered to be part of conventional medicine (www.nccam.nih.gov). The major types of CAM are (1) alternative medical systems such as acupuncture, homeopathic and naturopathic medicine, (2) mind-body-interventions including meditation, prayer or mental healing, (3) biologically based therapies using herbs, foods, and vitamins, (4) manipulative and body-based methods such as chiropractic or osteopathic manipulation and massage and (5) energy techniques comprising biofield therapies (e.g. qi gong, reiki, therapeutic touch) and bioelectromagnetic-based therapies (e.g. impulse magnetic-field therapy). People who prefer CAM over conventional medicine take CAM for "holistic", "more natural", "good for body and soul" and "free of side-effects" and they may argue that such therapies are better for there child than conventional ones. However, there is only some scientific evidence regarding some CAM therapies, and this evidence is largely based on studies in adults. Recurrent headache is an important cause of distress and disability in children and adolescents and requires effective treatment. Regarding the use of CAM therapies one must consider (1) the lack of reliable controlled studies on efficacy as well as safety of these therapies, (2) the large proportion of young headache patients responding favorably to placebo, and (3) the risk that (uncritical) use of CAM therapies and (unfounded) scepticism against conventional medicine may prohibit an effective treatment of disabling headaches. A CAM therapy might be useful in selected patients and it should not be forbidden or broken off in subjects using it successfully (provided that it is not harmful), but the lack of reliable data does not justify a general recommendation of any CAM treatment for treating headache in children and adolescents.

\section{L-9} NEUROPHYSIOLOGICAL ASPECTS OF PSYCHIATRIC
COMORBIDITY AND NEUROTICISM IN PEDIATRIC MIGRAINE

M. Siniatchkin, W.D. Gerber, U. Stephani

Department of Pediatric Neurology and Department of Medical Psychology, University of Kiel, Kiel, Germany; e-mail: m.siniatchkin@pedneuro.uni-kiel.de

Migraine in children is characterized by high psychiatric comorbidity with especially internalizing disorders (anxiety disorders and depression). Strong association between migraine and neuroticism has also been demosntrated in a number of studies. The contingent negative variation $(\mathrm{CNV})$ - a slow event-related potential, which represents different stages of information processing - is sensitive to changes of internalizing behavioral characteristics and was closely related to neuroticism. The higher neuroticism, the larger the amplitude of the early CNV component, the 
more pronounced the loss of CNV habituation. Migraine patients are characterized by high $\mathrm{CNV}$ amplitudes and reduced habituation. The present study investigates the relation between $\mathrm{CNV}$, anxiety/depression, abnormal parent-child interactions and neuroticism in families with a migraine child. The results show that the more restrictive behavior during parentchild interactions was demonstrated towards a migraine child, the higher neuroticism and anxiety scores in this child corresponding with more abnormal CNV characteristics. The comparison between migraine families with and without psychiatric comorbidity reveilied more pronounced CNV abnormalities in comorbide cases. This study provides an evidence for neurophysiological basis of psychiatric comorbidity in migraine which may be related to abnormal information processing representing neuronal sensitivity and central disposition. The interplay of genetic and environmental factors within this disposition could be proposed.

\section{L-10 \\ THE MENTAL MAKE-UP OF THE (YOUNG) MIGRAINE PATIENT: THEIR PERSONALITY AND WAYS OF COPING} J. Passchier

Erasmus University, Medical Center Rotterdam, NIHES, Rotterdam, The Netherlands; e-mail: j.passchier@erasmusmc.nl

Since 1949, many investigations have been devoted to find evidence for the so-called "migraine personality", that consists of anxiety, obsessivecompulsiveness, depression, perfectionism, achievement motivation and fear of failure. Generally, in about 50 years of research, the evidence for a higher prevalence of such traits among migraine patients can be considered to be conflicting. Higher average anxiety, depression and achievement motivation scores have indeed been found for migraine patients, but not consistently and often not in a clinical degree. Those who consult the clinician are generally more anxious and depressed than those who are not, but this is not specific for migraine. Similar findings have been reported for children and youngsters with migraine and chronic headache. Since raised scores on anxiety and/or depression have also been found in children with chronic pain at other locations than the head, their abnormal scores have been interpreted by some investigators as being caused by suffering from chronic pain. Our group performed a study in about 200 adolescents with chronic pain from the general population. We found that those patients who had higher anxiety and depression, did also have more headache and a lower quality of life than those who had normal scores. In the past two decades, more research attention became devoted to the strategies that patients used to cope with their pain. It was generally found that patients with a non-life threatening disease, who take actions to fight their physical complaints, are better off. This seems not the case for chronic headache; however. We found no associations between active, problem-focussed coping and the amount of pain in youngsters with chronic headache or between this type of coping and their quality of life. In line with the coping literature, an other group of strategies appeared to be more relevant, namely emotion-focussed coping, in particular coping by ruminating, worrying and exaggerating the consequences of the pain. Those of our youngsters who applied this strategy in particular, had not only more pain, but also a lower quality of life in comparison with the others. This finding suggests that cognitive-behavioral techniques for chronic headache in children can help them both with prevention of headaches and with the reduction of its consequences.

\section{L-11 \\ RELATIONSHIP BETWEEN MIGRAINE AND STROKE IN PAEDIATRIC AGE}

L.N. Rossi

Department of Paediatrics, University of Milan, Italy; e-mail: livia.rossi@unimi.it

According to the IHS classification published in 2004, "migrainous cerebral infarction" is a cerebral infarction occurring during the course of a typical migraine attack with aura. The following conditions should be present: (1) the attack should be typical of previous attacks except that one or more aura symptoms persists for $>60$ min; (2) neuroimaging demonstrates ischemic infarction in a relevant area; (3) the symptom should not be attributed to another disorder. In this way, the IHS definition of migraine-induced stroke is restrictive as it does not allow the diagnosis in patients who previously had migraine without aura. There are few studies on migrainous stroke in pediatric age. The reported patients had at least one episode of infarction with symptoms which were characteristic for migraine. Some children had more than one episode with stroke or with neurological deficit and presumed stroke, and these episodes were all on the same side. Therefore, it is quite reasonable to presume that an infarct tends to occur more easily when the same cerebral area is recurrently involved. Frequently the area of infarction was in the posterior cerebral artery territory, in contrast to what is usually found in stroke of idiopathic origin; angiography showed a transient segmental narrowing in some of the cases. In almost all cases described in pediatric age recovery was complete or almost complete. IHS criteria for migrainous stroke are not fulfilled for the cases of pediatric age in which an exclusion of other causes of stroke was inadequate. Furthermore, children reported in literature as migrainous stroke cases do not fulfill all IHS criteria for migrainous cerebral infarction because most of them did not have previous migraine with aura and some of them were not affected by previous migraine attacks at all. However, it is well known that in children an attack of complicated migraine can be the begin of a migraine history. The relationship between migraine and stroke in paediatric age needs further studies.

\section{L-12 \\ THE EFFECTIVENESS OF HOSPITALISATION IN THE TREATMENT OF PAEDIATRIC IDIOPATHIC HEADACHE PATIENTS}

${ }^{1}$ G. Lanzi, ${ }^{1,2}$ S. D'Arrigo, ${ }^{1}$ O. Ferrari-Ginevra, ${ }^{1}$ M. Rossi, ${ }^{3} \mathrm{C}$. Termine ${ }^{I}$ Department of Child Neurology and Psychiatry, IRCCS “C. Mondino Foundation”, University of Pavia; ${ }^{2}$ Department of Child Neurology, C. Besta Institute, Milan; ${ }^{3}$ Child Neuropsychiatric Unit, University of Insubria, Varese, Italy; e-mail: glanzi@unipv.it

Objective The idea for this study derived from the clinical impression that paediatric headache patients might benefit more from inpatient than outpatient care.

Methods The study population included 27 girls and 23 boys aged eight through 18 years with migraine or tension-type headache. Children were randomised to hospital admission or outpatient assessment and followed for six months.

Results Compared to outpatient assessment, hospital admission was correlated to a significant increase in the number of responders: 0 vs $44 \%$ (one month), 0 vs $68 \%$ (three months), and 12 vs $68 \%$ (six months). Logistic regression analysis confirmed the high response rate among hospitalized patients after adjusting for age, sex, diagnosis, and headache characteristics or admission.

Conclusions We think hospitalisation reduces the emotional mechanisms that provoke stress in children and often induce or favour headache attacks. If these mechanisms can be interrupted, the management of disease may become easier and with enduring benefits.

\section{L-13}

BURDEN OF HEADACHE: WHAT IS IMPORTANT IN ADULTS?

\section{T. Steiner}

Division of Neuroscience, Imperial College, London, UK; e-mail: t.steiner@ic.ac.uk 


\section{L-14 THE BURDEN OF HEADACHE. WHAT IS IMPORTANT IN CHILDREN?}

L. Metsähonkala

Department of Child Neurology, Turku University Hospital, Turku, Finland; e-mail: liisa.metsahonkala@tyks.fi

Recurrent headache is a common problem already in children and adolescents. It is the most prevalent type of recurrent pain in children. In some aspects, childhood headache is less severe than headache in adults; the prevalence of chronic headache is lower and the headache episodes are shorter in children than in adults. Several recent studies on adults have investigated both the personal, social and societal burden of headache in adults. Far less is known about the burden of headache in children. It is probable that adults, both parents and doctors, are prone to estimate the burden of headache in children inaccurately. Like in adults, recurrent headache influences school, hobbies and socia relations of the child. In studies on quality of life in children, headache intensity, duration and frequency seem to have impact on the daily and leisure activities. In a recent study, it was noticed that the impact of chronic daily headache and of migraine on the quality of life of children in a clinical setting is as heavy as of some other chronic illnesses such as cancer or arthritis (Powers et al., 2003). In some aspects, headache is even a harder threat to the quality of life of the child than of the adult. For the first, development is learning. A child is expected to be creative and to learn new things every day, a very demanding task which is certainly affected by recurrent headache. For the second, headache does not affect only the child but the life of the whole family. A third important aspect is that most people start to have headache in childhood or in adolescence. The proneness to headache is an inherited trait. During the early years, children and adolescents learn to cope with their headache, to control their pain and to control the headache frequency. The burden of headache later on partly depends on this learning process. Childhood and adolescence is the time to try to inhibit the headache from becoming a chronic problem.

\section{L-15 \\ EUROPEAN INITIATIVES AGAINST CHRONIC PAIN IN CHIL- DREN AND ADOLESCENTS}

\section{S. Erdine}

Department of Algology, Medical Faculty of Istanbul University, Istanbul, Turkey; e-mail: algomed@superonline.com

\section{L-16 \\ POST-TRAUMATIC HEADACHE ATTRIBUTED TO MODER- ATE HEAD INJURY IN GROWING UP AGE, REAL ENTITY OR} ACCIDENTAL EVENT?

D. Moscato, M.I. Peracchi, ${ }^{\circ}$ G. Mazzotta, ${ }^{\circ}$ L. Savi, ${ }^{\circ 0}$ P. Battistella Childhood Headache Centre, Rome; 'Neurological Clinic, Perugia University; ${ }^{\circ}$ Headache Centre, Le Molinette Hospital, Turin; ${ }^{\circ 0}$ Pediatric Department, University Padova, Italy; e-mail: d.moscato@idi.it

Post-traumatic headache (PTH) often arises in children and adolescence from $30 \%$ to $70 \%$. However, headache is often caused by severe head injury, accompanied by other symptoms (dizziness, nausea,vertigo, difficulty in concentrating, insomnia, etc.) and, therefore, it is often a part of a post-traumatic syndrome, rather than headache for itself and in these cases the causation link is well evident. A problem, conversely, arises in the event of PTH attributed to mild head injury (MHI), in which the identification of the causation link is difficult, as well as the definition of PTH or Migraine or TTH triggered by a trauma. The new classification gives very precise indications: the onset $<7$ days after, the duration $<3$ months for acute, $>3$ for chronic. The reason for the above is that also headache is considered among the various sequences and, therefore, it must also disappear together with other disturbances deriving from the trauma. We have evaluated the incidence of PTH attributed MHI from two standpoints. In the population reporting to a hospital emergency room, in the activity of 4 Italian paediatric headache centres. Here the data of first six months of the study. Cranial traumas have been controlled by the Emergency Room of San Carlo IDI Hospital of Rome for six months: 463 cases, 157 aged 3-18 years, of these 56 were secondary to MHI. The latter 56 (43 M,14 F) have been examined one and eight weeks after the event, evaluating the type of traumas, the neurological examination, the development of headache, the associated symptoms. All of them showed neurological Examination, X-rays, NMR(4) negative. The causes of the traumas: road accidents 2 , household 19 , school 14 , sports 8 , aggressions 3.7 showed acute PTH, (5 similar ETTH); 8 a chronic PTH (4 CDH), which in the majority 10 had ceased after 6 months. Preceding headache: ETTH 4. Migraine 3. Associated symptoms: vertigo 25, changes in humour 12 , alteration of the wake sleep rhythm 12 , sleep disturbances 12 . In the headache centres 752 patients have been examined for the first time (410 F, 342 M) aged 4-18 years. The diagnoses 3.2\% had PTH (onset within 2 months) acute 2 boys, chronic 22 (9 F, $13 \mathrm{M}$ ). Succeeding headache MwoA 12, MWA 1, TTH7 CDH4. 17 patients had family history for headache. 10 already showed headache; head injury in $58 \%$ linked to playing, $42 \%$ to road accidents. Sleep disturbances already existing prior to the trauma (talking in the sleep, bruxism, nightmares, difficulty in getting to sleep) have appeared increased by 20\%-30\%; episodes of aggressiveness and panic crisis have also appeared in $20 \%$ of the cases. If, on one hand, the above data confirm the poor evidence of headache following a MHI, on the other hand, they make it doubtful the very existence of this entity; it may even seem that it is more a triggering factor of headache pathologies already existing before, but which had not yet actually had an event that triggered the birth of the pathology; this is confirmed by the fact that later in time these pathologies continue to appear and, therefore, the head injury is more the solvent moment of headache history. The above are initial data and the number of patients is not high, but if they are confirmed, then they might indicate the poor consistency of this headache as an independent pathology.

Suggested readings

- Haas, DC, Pineda GS, Lourie (1975) Archives of Neurology 32:727-730

- Lanser JBK, Jennekins-Schinkel A, Peters ACB (1988) Headache 28:229-230

- Lanzi G, Balottin U, Borgatti R, De Agostini G, Pezzotta S, Spanu G (1985) Cephalalgia 5:211-15

- Raskin NH, Appenzeller O (1980) Headache Sanders Company 7:199-209

\section{WORKSHOP}

\section{W-1 \\ NONPHARMACOLOGICAL TREATMENT APPROACHES FOR PEDIATRIC HEADACHE: RESEARCH BASE, PRACTICE CONSIDERATIONS \\ ${ }^{1}$ F. Andrasik, ${ }^{2}$ W.D. Gerber, ${ }^{3}$ L. Grazzi, ${ }^{4}$ I. Pirker-Binder, ${ }^{5}$ U.K. Haller, ${ }^{6} P$. Jordanidis \\ ${ }^{1}$ Institute for Human and Machine Cognition, University of West Florida, Pensacola, FL, USA; ${ }^{2}$ Institute for Medical Psychology, University of Kiel, Germany; ${ }^{3}$ Neurological Institute C. Besta, Milan, Italy; ${ }^{4}$ Association for International Stressmanagement and Biofeedback and Coaching ASTI, Vienna, Austria; ${ }^{5}$ Headache Unit, Dept. of Neuropsychiatry of Childhood and Adolescence, Medical University of Vienna, Austria; ${ }^{6}$ Biofeedback, Hypnosis and Stress Management Center, Thessaloniki, Greece}

This workshop, chaired by Dr. Andrasik, will address the array of nonpharmacological approaches that, with children and adolescents, can 
serve as treatment adjuncts and treatment alternatives to pharmacological approaches. The workshop will begin with a brief review of the empirical support for a number of nonpharmacological approaches currently being used (presented by Dr. Andrasik). Most attention will be devoted to the more common and routinely used approaches of relaxation, biofeedback, and stress management. The less common approaches, such as visual modulation, TENS, acupuncture, and dietary, will be reviewed only in brief. New work, involving a special EEG approach based on contingent negative variation, will be presented as well (by Dr. Gerber). Having reviewed the empirical support for these approaches, the focus will turn to practice issues (presented by Dr. Grazzi, Dr. Jordanidis, Ms. Pirker-Binder and Ms. Haller). The following topics will be addressed here: integrating and sequencing multi- ple approaches, combining nonpharmacological and pharmacological treatments, organizing training sessions, dealing with collateral conditions that can compromise or interfere with treatment, and adapting procedures to fit the developmental levels and learning styles of children and adolescents. If possible, the presenters will provide an actual demonstration of basic biofeedback approaches.

Target audience This workshop is open to professionals of all disciplines and all levels. It assumes no prior experience; only a healthy interest on the topic.

Workshop objectives (1) Become knowledgeable about the scientific support for nonpharmacological approaches. (2) Understand the theory and approach for EEG biofeedback treatment. (3) Learn how to apply these procedures successfully in the practice setting. 
ORAL PRESENTATIONS

\section{0-01 \\ DECREASING THE MINIMAL DURATION OF THE ATTACK TO 1 HOUR IS SUFFICIENTLY TO INCREASE THE SENSI- TIVITY OF THE ICHD-II FOR MIGRAINE IN CHILDHOOD?}

M.A. Arruda, C.A. Bordini, M.C. Ciciarelli, J.G. Speciali

Neurology Department of the Ribeirão, Preto Clinical Hospital, São

Paulo University, Brazil; e-mail: brheadache@netsite.com.br

To ascertain the second edition of the International Classification of Headache Disorders (ICHD-II) in 489 children (range, 2-12 years) with chronic headaches consecutively attended at a pediatric headache clinic (mean follow-up, 16.1 months). The initial diagnosis was retrospectively made according to the ICHD-II and the final diagnosis prospectively, based on the Longitudinal Intuitive Clinical Diagnosis (LICD) deemed to be the gold standard. Accordingly ICHD-II migraine without aura diagnosis had the following scores: sensitivity $52 \%$, specificity $100 \%$, predictive positive value $100 \%$; whist for frequent episodic tension-type headache the respective values were $100 \%, 95 \%$ and $45 \%$. The ICHD-II criteria for migraine without aura have a high specificity but low sensitivity in childhood, even considering the minimal duration of the attacks to be 1 hour. Herein is shown that aspects concerning the pain characteristics and accompanying symptoms of migraine in childhood and the existence of "probable tension-type headache" subgroup play an important role in the low sensitivity of ICHD-II criteria for migraine in at this age.

\section{0-02}

MODIFIED DIAGNOSTIC FLOW CHART TO DIFFERENTIATE EPISODIC TENSION TYPE HEADACHES FROM EPISODIC MIGRAINES IN CHILDREN AND ADOLESCENTS

M.V. Francis

Headache and Migraine Research Centre Cherthala, India; e-mail: vfrancis@rediffmail.com

Objectives To design a diagnostic flow chart to differentiate episodic tension type headaches from episodic migraine headaches in children and adolescents

Background IHS episodic tension type headache and episodic migraine diagnostic criteria have more than one overlapping statements. No significant study has been done to clearly differentiate between the two entities.

Methods 617 children and adolescents who initially presented with IHS episodic tension type headaches(2.1 and 2.3) were identified later when they presented with migraine features(IHS 1(1.1 and 1.2), IHS R, IHS RR 2001 MODIFIED). Parenteral migraine history and common migraine triggers were the most helpful differentiating features. Migraine trait symptoms were also helpful in some.

Results (The diagnostic flow chart - details in the text) The important features are recurrent headpain, activity affected or not, autonomic symptoms present or not. Common migraine triggers, migraine parents or siblings and migraine trait symptoms were also considered.

Conclusions The diagnostic flow chart is the most simple way of clinically differentiating episodic tension type headaches from episodic migraine headaches in children and adolescents.

\section{0-03}

FAMILY-BASED ASSOCIATION STUDY OF POLYMORPHISMS OF THE DOPAMINERGIC SYSTEM IN PEDIATRIC MIGRAINE

1,2Á. Szilágyi, 1, ${ }^{2}$ K. Boór, ${ }^{3}$ I. Orosz, ${ }^{3} H$. Kalász, ${ }^{2}$ M. Sasvári-Székely, ${ }^{3}$ V Farkas

${ }^{1}$ Department of Pharmacology and Pharmacotherapy; ${ }^{2}$ Department of Medical Chemistry, Molecular Biology and Pathobiochemistry;
${ }^{3}$ Department of Pediatrics, Semmelweis University, Budapest, Hungary; e-mail: szilagyi@puskin.sote.hu

In pediatric migraine patients some of the prodromal and attack symptoms could be interpreted as alterations of the dopaminergic system. A VNTR in the 3' untranslated region of the dopamine transporter (DAT) gene as well as a $\mathrm{G}$ to A substitution located at the catechol-O-methyltransferase enzyme (COMT) gene may contribute to the altered function of the dopaminergic system. We investigated the polymorphisms of these 2 candidate genes by a genetic assosiation study. 87 affected families and 648 control persons were involved in case-control and in family-based (TDT) association studies. Pediatric patients were stratified according to migraine subtype (with or without aura) and the onset of disease $(<6$ years, respectively $>6$ years). Sample collecting was performed by a noninvasive process and genotype was determined by PCR based methods. Khi2 and TDT khi2 tests were used for statistical analyses. Our results indicate that the A containing genotypes of COMT are significantly more frequent among migraineurs with early onset of disease and the 10/10 genotype of DAT is significantly more frequent in the same group. The family based study confirmed our results showing more frequent transmission of the A containing and the 10-repeat alleles to offspring with early onset of migraine. These results suggest that the analysed polymorphisms may affect the onset of disease and confirm the involvement of the dopaminergic system in the pathomechanism of migraine.

\section{0-04}

MAGNETIC RESONANCE IMAGING (MRI) IN CHILDHOOD AND ADOLESCENCE WITH MIGRAINE (M) AND EPILEPSY (E): A CASE CONTROLLED STUDY

${ }^{I}$ A.S. Giannantoni, ${ }^{2}$ G. Tanfani, ${ }^{I}$ F. Galli, ${ }^{3}$ P.M. Russo, ${ }^{I}$ V. Guidetti

Department of Children and Adults Neurology and Psychiatry; ${ }^{2}$ Department of Neurosurgery and Facial Surgery; ${ }^{3}$ Department of Psychology, University "La Sapienza”, Rome, Italy; e-mail: v.guidetti@iol.it

Background Single or multiple hyperintense foci in the white matter have been reported on T2 weighted MRI in $12 \%-46 \%$ of adult M. Results of the recent studies showed certain correlation between transitory clinical manifestation with focal reduction of cerebral circulation and possible ischemic lesions in patients with $\mathrm{M}$.

Patients and methods We compared three groups of children: M, E and comorbid $(\mathrm{M}+\mathrm{E})$ to determine the frequency of MRI abnormalities, their location and any correlation with clinical and anamnestic data. 55 consecutive patients with M (80\% without aura (MO); $20 \%$ with aura (MA)) (range, 6-17; ma+10.9), 44 with Primary E (range, 2-17; ma 8.7) and $22 \mathrm{M}+\mathrm{E}$ (range, 4-15; ma 9.1) (IHS and ILAE classifications) performed MRI.

Results $M$ showed an incidence of focal white matter abnormalities in T2 weighted MRI higher than E $(23.6 \%$ vs $11.3 \% ; p<0.05)$, but lower than $\mathrm{M}+\mathrm{E}(23.6 \%$ vs $36 \% ; p<0.05)$. MO>MA ( $71 \%$ vs $29 \% ; p<0.01)$. Lesions are predominantly located in centrum semyovals independently of the side of M or aura. Risk factors for MRI abnormalities seem to be cardiovascular disease in fathers $(p<0.01)$ and $\mathrm{M}$ in the mothers $(p<0.04)$. Frequency, length, intensity of attacks did not predict the association with white matter abnormalities. Conclusions $\mathbf{M}$ may be associated with early pathologic changes in the brain.

\section{$0-05$}

SERIOUS BRAIN DISORDERS AMONG CHILDREN AND ADOLESCENTS WITH CHRONIC HEADACHE

I. Abu-Arafeh

Fraser of Allender Neurosciences Unit, Royal Hospital for Sick Children, Glasgow, UK; e-mail: ishaq.abu-arafeh@fvah.scot.nhs.uk

Background Brain tumours are the common concerns for parents and primary care doctors on evaluating a child with chronic headache. The 
aim of this study is to quantify the risk of serious neurological disease in children and adolescents with chronic headache.

Methods All children attending a specialist headache had clinical assessment, brain neuroimaging (CT or MRI) where indicated and follow up using prospective headache diaries.

Results Eight hundred children and adolescents between 1.25 and 18.75 years of age (mean 10.7; SD 2.9) were evaluated. At first presentation to the clinic they had suffered from headache for at least 1 month (range, 1 month - 12 years; mean 21 months: SD 22). 141 children $(18 \%)$ were investigated with either CT or MRI scan of the brain, including 88 who were investigated by their referring doctors before attending the clinic. Three children $(0.375 \%)$ had significant neurological cause for their headaches. The diagnosis of brain tumour was unexpected in only one child $(0.125 \%)$ who had headache for 4 years. Headache changed from tension to migraine and lastly to non-specific despite a persistent normal examination. The MRI scan of the brain showed posterior fossa tumour and hydrocephalus.

Comments Brain tumours presenting with long-standing headache in children are rare. Serious disorders should be suspected in children with subtle changes in the patterns of headache, personality and behaviour.

\section{0-06 \\ FAMILIAL OCCURRENCE OF PSYCHIATRIC DISORDERS IN HEADACHE, ASTHMATIC, EPILEPTIC AND HEALTHY CHIL- DREN: A CONTROLLED STUDY}

${ }^{I} \mathrm{~F}$. Galli, ${ }^{1} \mathrm{~V}$. Guidetti, ${ }^{2} \mathrm{~F}$. Tagliente

${ }^{I}$ Department of Child Adol Neurol and Psychiatry, University "La Sapienza”, Rome, Italy; "2Department Child Adol Neurol and Psychiatry, University "Federico II", Naples, Italy; e-mail: f.galli@chiadache.org

Introduction The comorbidity of headache $(\mathrm{H})$ and psychiatric disorders (PSY DIS) is high both in adults and children or adolescents. The explanation of such association is far to be understood (shared genetic or biological factors? Cause-effect?), and could bring light on pathophysiology and treatment of $\mathrm{H}$ disorders. Main aim is analysing the occurrence of PSY DIS in parents of $\mathrm{H}$ patients.

Materials and methods 100 parents of $\mathrm{H}$ children (range 6-12; m.a. 9.06) seen in the $\mathrm{H}$ Center and parents of three samples (100 chronic asthma, 92 epileptic (third level Centers) and 100 healthy subjects (routine visits in paediatric settings)) have been interviewed for analysing the occurrence of H (IHS 1988 criteria) and PSY DIS, by the mean of structured interview (Symptom Questionnaire, Fava et al.,1982). Student's T test and chi-squared has been performed.

Results Parents of $\mathrm{H}$ patients showed $43.5 \%$ of PSY DIS (95\% on maternal side) and the highest scores on anxiety, mood and somatization scales $(<0.001$ vs healthy controls). Similar trend $(p=n s)$ for $\mathrm{H}$, epileptic and asthmatic samples for anxiety and somatization scales and for $\mathrm{H}$ and epileptic samples for depression scale. Parents of chronic daily $\mathrm{H}$ patients have the highest number of PSY DIS compared to $\mathrm{H}$ and not-H patients.

Conclusions The high prevalence of PSY DIS also in parents of $\mathrm{H}$ sufferers open new directions of research to understand the meaning and discussing the similarity and differences of $\mathrm{H}$ and other disorders with onset.

\section{0-07 \\ COPING WITH PEDIATRIC HEADACHE: PAIN-SPECIFIC COPING RESPONSES AND HABITUAL COPING STYLES}

L. Morris, M. Heinrich, B. Kröner-Herwig

Department of Clinical Psychology and Psychotherapy, University of Göttingen, Göttingen, Germany; e-mail: lmorris@uni-goettingen.de

The number of children and adolescents suffering from headache has increased substantially in the past decades. Accordingly, identifying factors that contribute to the development and maintenance of pediatric headache has gained importance. Headache-related coping responses and habitual coping styles are potentially interesting factors in this context. In the present study, questionnaires developed to address these issues were administered via postal survey to a community-based sample of 100 households with a child between 7 and 14 years of age (pilot study). Pain-specific coping responses reported in the literature and items of the Coping with Stress Questionnaire - Child and Adolescent Version (Hampel, Petermann and Dickow, 2001) were integrated in the survey measures. Questionnaires were returned by $82 \%$ of the sample. Headaches, experienced monthly or more often, were reported for $18 \%$ of the children. Less frequent headaches were reported for $27 \%$. The most frequent coping strategies employed by children during a headache episode included (in descending order) sleeping, lying down, relaxing, and cooling their forehead. Physicians were consulted regarding headache by $27 \%$. The habitual coping styles of children with headache differed significantly from children without: escape avoidance and ruminative coping styles were significantly more prevalent in children with headache. Further and more detailed results based on a larger sample (main study, $\mathrm{n}=8800$ ) will also be presented.

\section{0-08}

\section{THE COGNITIVE IMPACT OF MIGRAINE IN CHILDREN}

R.K. Cady, K.U. Farmer

Headache Care Center, Springfield, Missouri, USA; e-mail: kfarmer@primarycarenet.org

Objective To investigate the cognitive efficiency of children during migraine, compared to a nonmigraine period, and recovery of cognition following treatment.

Methods Subjects: 10 subjects, 3 males and 7 females, ages 8 to 12 (mean 10.3) participated. Measure: The Migraine Early Warning Tool (MEWT) is an automated neuropsychological assessment metrics consisting of 4 valid and reliable subtests, programmed on a Palm m100. The Performance Index (PI) is a measure from 0 to 9 which rates the subject's overall performance on the 4 subtests compared to that person's performance at screening. Procedure: subjects took the MEWT 4 times at screening and daily. Baseline period: for 4 weeks, subjects treated migraines in their usual fashion with over-the-counter (OTC) remedies. They took the MEWT right before medication and at 2 hours post-dose. Treatment period: for 4 weeks, subjects treated migraines with an oral triptan. They took the MEWT before medication and at 2 hours post-dose.

Results The Performance Index (PI) dropped from 9 to 6 prior to a migraine, indicating a drop in cognitive efficiency and warning the subjects of an impending attack. Two hours post-dose, the PI rose to 8 using OTCs and to 9 with triptan.

Conclusions Migraine produces a significant drop in cognitive efficiency which recovers with treatment. A triptan facilitates recovery more rapidly than an OTC

\section{0-09}

\section{ARE PARENTS AWARE OF THEIR SCHOOLCHILDREN'S HEADACHES?}

${ }^{I}$ T. Sasmaz, ${ }^{1}$ R. Bugdayci, ${ }^{2} A$. Özge, ${ }^{2}$ A. Karakelle, ${ }^{1} \mathrm{O}$. Kurt, ${ }^{2} \mathrm{H}$. Kaleagasi

${ }^{1}$ Public Health and ${ }^{2}$ Neurology Departments, Mersin University, School of Medicine, Mersin, Turkey; e-mail: aozge@mersin.edu.tr

Background The objective of this study is to determine parents' awareness of their children's headaches and to evaluate some of the factors that affect this awareness.

Methods The subjects of the study are 2601 children who were diagnosed with headache. Data on the children and the parents was collected using a detailed data form. The diagnosis of headache in children 
was made on the basis of the criteria of the International Headache Society (IHS). If the parents of a child diagnosed with headache reported that their child had headache, the parent was evaluated to be aware of his/her child's headache. In the statistical analyses, chi-square and binary logistic regression were used.

Results Almost $74 \%$ of parents were aware of their children's headache. It was found that migraine type headache, female gender, being the first child of the family, travel sickness of children, the presence of headache history in one of the family members; the number of family members and mother's age are factors that affect the awareness level of parents. It was also revealed that parents who do not work outside are more aware of their children's headache and that educational and financial status do not have any effect on the degree of awareness.

Conclusions In a city like Mersin, which is economically well developed when compared with the rest of the country, one quarter of the parents are not aware of their childrens' headache.

\section{0-10 CHANGING CLINICAL MIGRAINE PICTURE FROM CHILD- HOOD TO ADOLESCENCE}

\section{T. Jun}

Teramoto Neurology Clinic, Nagoya, Japan; e-mail: teramoto-nc@nifty.com

Background The clinical picture of migraine in children and adolescents was different from that in adults. Since there are few reports on the clinical picture for each generation, we undertook this study. Patients and methods Totally 311 patients (138 boys and 173 girls) were investigated in the study. The patients were divided into four age groups of 3 years each; 7-9, 10-12, 13-15 and 16-18 years old. The number of the cases was $49,83,88$ and 91 , respectively, in each group. We compared the clinical findings at the first consultation for each patient. We checked the male/female ratio,side of the pain, nature of the pain, exsistence of premonitory signs, vertigo and/or dizziness and daily appearance of attacks.

Results The ratio of males was $53.1 \%, 57.8 \%, 43.2 \%$ and $34.1 \%$ in that order. Unilaterality of the headaches was $37.4 \%, 42.0 \%, 56.6 \%$ and $73.5 \%$, respectively. Pulsating quality was $4.1 \%, 30.1 \%, 36.4 \%$ and $47.3 \%$, while patients with any premonitory signs were $22.4 \%$, $34.9 \%, 44.3 \%$ and $64.5 \%$. Vertigo and/or dizziness associated with headache were $16.3 \%, 22.9 \%, 10.2 \%$ and $8.9 \%$, and morning dominant attack cases were $20.4 \%, 44.6 \%, 26.1 \%$ and $14.3 \%$, respectively.

Conclusions The present study revealed that the clinical picture of migraine in childhood and adolescents is gradually changing to that for adults with aging. There are no reports on the correlation between the clinical picture and aging. The present study may therefore be useful for the diagnosis of migraine in childhood and adlescents.

\section{0-11}

\section{CHILDHOOD AND ADOLESCENT RISK FACTORS FOR MIGRAINE AND TENSION-TYPE HEADACHE}

\section{${ }^{1} K$.E. Waldie, ${ }^{2} R$. Poulton}

${ }^{I}$ Centre for Cognitive Neuroscience, Department of Psychology, University of Auckland, Auckland, New Zealand; ${ }^{2}$ Dunedin Multidisciplinary Health and Development Research Unit, Department of Preventive and Social Medicine, Dunedin School of Medicine, University of Otago, New Zealand; e-mail: k.waldie@auckland.ac.nz.

Physical and psychological measures across the lifespan were used to determine which factors could differentiate between migraine and tension-type headache in a representative birth cohort (Dunedin Multidisciplinary Health and Development Study). Over one-third of the study members suffered from frequent headache during childhood. Of these children, over one quarter were later diagnosed with primary headache in adulthood. The 1-year prevalence was $11.1 \%$ for tension- type headache and was $11.6 \%$ for migraine. Migraine at age 26 was predicted by maternal headache, anxiety disorders in childhood and adolescence, and stress reactivity and harm avoidance personality traits. In contrast, tension-type headache was characterised by childhood neck or back injury, moderate childhood anxiety, and adolescent aggression. Perinatal complications, neurological disorders or concussion did not predict headache status. While migraineurs had the most severe impairment in work and social-related activities, all study members diagnosed with primary headache disorder reported their physical, emotional and mental health to be worse than headache-free controls and comparable to individuals currently receiving treatment for asthma. The pervasive impairment reported across multiple life domains among young headache sufferers illustrates the significant burden of illness associated with headache disorders. These results also confirm that migraine and tension-type headache are distinct disorders with different defining characteristics.

\section{0-12}

\section{MENSTRUAL MIGRAINE (M) IN ADOLESCENCE: A POPU- LATION BASED-STUDY}

\section{${ }^{1}$ F. Tagliente, ${ }^{2}$ F. Galli, ${ }^{2}$ A. Pascotto, ${ }^{2} V$. Guidetti}

${ }^{I}$ Department of Child and Adol Neurol and Psychiatry, II University of Naples; "2University "La Sapienza", Rome, Italy; e-mail: v.guidetti@iol.it

Background Epidemiologic data and clinical observations suggest an association between $\mathrm{M}$ and menstrual (Me) cycle. The relationship has been widely described in adults: no data in children and adolescents.

Aim Assessing the prevalence and the clinical features of Me-related headaches in a female adolescent population.

Materials and methods 520 students (range, 13.1-20.6; m.a.: 16.2) randomly selected at school. A questionnaire had been administrated regarding headache $(\mathrm{H})$, menarche and menses. Questions on family history of M and Me M were included. IHS criteria (1988) plus MacGregor's stricter definition of "Me M" had been applied.

Results Median age at onset of H: 12.4 years. Primary $\mathrm{H}$ in 69\%: 20\% $\mathrm{M}$ without aura (MO), 2\% M with aura, 33\% tension type (TTH), 23\% mixed $\mathrm{H}$; in $22 \% \mathrm{H}$ was not classifiable. Only those with $\mathrm{MO}$ and TTH were subsequently analysed. Of all MO, Me M was observed in $2.7 \%$, pre-Me $\mathrm{M}$ in $16.6 \%$ and $\mathrm{Me} \mathrm{M}$ in $27.8 \%$; no link with Me cycle in $52.8 \%$ of M. TTH was associated to the pre-Me period in $18 \%$ of cases, to Me period in almost $1 \%, 16.8 \%$ was Me associated, whereas $63.8 \%$ of TTH was not related to Me.

Conclusions M may occur at any time during the Me cycle. However, $\mathrm{Me} \mathrm{M}$ in adolescence rarely occurs, involving less than 3\% of our population, lower than adults. It may be due to the irregularity of $\mathrm{Me}$ cycle during the first gynaecological years. Further studies are needed to corroborate these data and investigate the association between female hormones and $\mathrm{H}$.

\section{0-13}

DYSMENORRHOEA: A MIGRAINE TRAIT OR ABDOMINAL MIGRAINE

\section{M.V. Francis}

Headache and Migraine Research Centre Cherthala, India; e-mail: mvfrancis@rediffmail.com

Objective To study menstrual origin abdominal pains in mothers of migraine children.

Methods In this study spanning 3 years, 1800 IHS migraine (1.1 and 1.2) mothers were questioned regarding menstrual pains (headpain and abdominal pain), when they presented with their children with headaches. Results While only $14 \%$ (252) had menstrual migraine (day 1 plus or minus 2 days of the menstrual cycle), 76\% (1362) reported dysmenorrhoea either at the time of presentation or sometime in the past 
(mostly before first pregnancy) and in 64\% (1.152) dysmenorrhoeic severe lower abdominal pains lasting for a day were associated with nausea or vomiting and phonophobia, all suggestive of a diagnosis of abdominal migraine.

Conclusions This study concludes that abdominal pains resembling migraines are very common in female migraineurs during menstruation and it can occur without typical IHS migraine or migrainous disorders (1.7). Dysmenorrhoea present or past must be specifically enquired into while taking headache history from mothers and if it can be considered as a migraine trait in mothers, diagnosing early migraines in their children will be made easier.

\section{0-14 \\ TOPIRAMATE FOR MIGRAINE PREVENTION IN CHILDREN: A RANDOMIZED, DOUBLE-BLIND, PLACEBO-CONTROLLED \\ TRIAL \\ ${ }^{1}$ P. Winner, ${ }^{2}$ E.M. Pearlman, ${ }^{3}$ S. Linder ${ }^{4}$ D. Jordan ${ }^{4}$ A. Fisher ${ }^{4} J$. Hulihan ${ }^{I}$ Palm Beach Headache Center, West Palm Beach, Florida; ${ }^{2}$ Savannah Neurology, Savannah, GA; ${ }^{3}$ Dallas Pediatric Neurology Association, Dallas, TX; ${ }^{4}$ Ortho-McNeil Pharmaceutical, Raritan, NJ; e-mail: pwinner777@aol.com}

Background Topiramate (TPM) effectively prevents adult migraine. Migraines occur in up to $10 \%$ of children but treatment options are limited. The efficacy and tolerability of TPM in the pediatric population is not known.

Methods The efficacy of TPM in 162 children with migraine (age, 6-15 years; $52 \%$ male) was assessed in a 20 -weeks pilot study (ITT population: TPM, $n=108$; placebo [PBO], $n=49)$. TPM was initiated at $15 \mathrm{mg} / \mathrm{d}$ and titrated over $8 \mathrm{wks}$ to $2-3 \mathrm{mg} / \mathrm{kg} / \mathrm{d}$, or maximum tolerated dose, whichever was less (maximum allowed dose was $200 \mathrm{mg} / \mathrm{d}$ ). Target dose was maintained for 12 weeks.

Results TPM reduced mean monthly migraine days by 2.6 (baseline = $5.4 \mathrm{~d}$ ), compared with $1.9 \mathrm{~d}$ for PBO (baseline $=5.5 \mathrm{~d}$ ), which approached statistical significance $(p=0.065)$. PBO migraine rates varied among age groups. A significantly greater percentage of TPM patients (32\%) had $275 \%$ reduction in mean monthly migraine days compared to PBO $(14 \%, p=0.020)$. Discontinuation rates due to adverse events were $6.5 \%$ for the TPM group and $4.1 \%$ for the PBO group. The most common AEs in TPM group were upper respiratory tract infection, anorexia, weight decrease, gastroenteritis, paresthesia and somnolence. The reported mean dose of TPM was $109 \mathrm{mg} / \mathrm{d}$ at end of study. Conclusions TPM has potential utility for pediatric migraine prevention and was well tolerated. Larger studies are warranted.

\section{0-15}

\section{QUALITY OF LIFE IN HEADACHE SUFFERING CHILDREN} AND ADOLESCENTS: SELF-REPORT AND PARENT-REPORT

${ }^{1}$ S. Solidei, ${ }^{1}$ E. Chicarella, ${ }^{2}$ P.M. Russo, ${ }^{1}$ F. Galli, ${ }^{2}$ G. Capacchione, ${ }^{I}$ V. Guidetti, ${ }^{2}$ C. Violani

${ }^{1}$ Department of Child and Ad Neurol Psychiatry; ${ }^{2}$ Department of Psychology, University "La Sapienza”, Rome, Italy; e-mail: v.guidetti@iol.it

Background The evaluation of Quality of Life (QOL) in children is different from adults, because it should take into account age-related characteristics. QOL instruments often do not consider the differences between parents and children in reporting the impact of headache on QOL.

Patients and methods 272 (158 F, $114 \mathrm{M}$ ) headache sufferers (9-15 years old; $\mathrm{M}=11.59 ; \mathrm{SD}= \pm 2.03)$ and their parents (192 mothers; 34 fathers; 59 both parents; 3 care takers) had been enrolled. Both children and their parents filled in the symptomatologic questionnaire and the Impact scale of the Headache Specific Quality of Life of Children (HSQOL-C), in its validated form.
Results Factorial Anova showed that the agreement parents-children is significantly higher for 12-15 years old than for 9-11 years old $[\mathrm{F}(1.255)=10.80 ; p=0.001]$. We found a higher level of congruence between child and parent reports for symptomatologic questionnaire (objective aspects) than Impact scale (subjective aspects). In the latter, headache sufferers obtained higher scores compared to their parents. Conclusions Agreement parents-children increases proportionately with children's age. It is likely due to the child's cognitive improvement, mental and language skills. QOL instruments should taken into account age-related characteristics of child development.

\section{0-16}

IMPACT OF MIGRAINE AND TENSION-TYPE HEADACHE IN CHILDREN AND ADOLESCENTS ON THE SUFFERER'S FAMILY: A CONTROLLED CROSS-SECTIONAL STUDY

A. Karwautz, G. Wagner, C. Wöber, A. Konrad, K. Schwienbacher, H. Buchegger, C.. Wöber-Bingöl

Headache Unit, Department of Neuropsychiatry of Childhood and Adolescents, Medical University of Vienna, Vienna, Austria; e-mail: andreas.karwautz@univie.ac.at

Background The psychosocial burden of headaches on families has rarely been studied in children and adolescents with migraine and tension-type headache.

Methods We investigated the psychosocial burden of headache on the

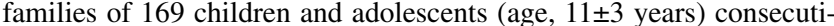
vely referred to our headache center. Headache was diagnosed according to ICHD-II (Cephalalgia 2004). Migraine without aura (MoA, ICHD-II 1.1, 1.6.1) was diagnosed in 113 patients $(66.9 \%)$, migraine with aura (MA, ICHD-II 1.2, 1.6.2) in $23(13.6 \%)$, and tension type headache (TTH, ICHD-II 2.2, 2.3, 2.4) in 33 patients $(19.5 \%)$. For assessing the psychosocial impact of headaches on families the Impact on Family Scale (German adaption by Ravens-Sieberer et al., 2001) was filled in by the mothers.

Results The time since onset of the headache was similar in patients with MoA, MA, and TTH. The general burden, financial, personal, daily and social burden as well as the prevalence of coping difficulties did not differ in the three groups. The impact of headache on the siblings, however, was significantly higher in families of patients with MoA (7.6 \pm 2.3$)$ than in those of patients with MA $(6.8 \pm 1.7)$ and TTH $(6.5 \pm 1.3)$, respectively.

Conclusions In the view of the mothers, MoA in children and adolescents has particular impact on the patients' siblings. Apart from that, the burden of headache on the family is similar in patients with MoA, MA and TTH.

\section{0-17 CHRONIC DAILY HEADACHE (CDH) IN CHILDREN AND ADOLESCENTS}

S.S. Seshia

Division of Pediatric Neurology, Department of Pediatrics, Royal University Hospital, Saskatoon, Saskatchewan, Canada; e-mail: sseshia@sasktel.net

Background Characterise $\mathrm{CDH}$ in those under 20 years of age. Material and methods Data on those referred with headache (HA) to the author's Private Practice Pediatric Neurology Clinic between September 1998 and December 2002 were entered prospectively and sequentially on standardised data sheets. Two hundred and forty $(33 \%)$ of 736 referred with $\mathrm{HA}$ had $\mathrm{CDH}$; of these, $196(82 \%)$ were followedup for 1 month to 3 years (median: 3 months) and are discussed further. Results There were $120(61 \%)$ females and 76 (39\%) males. Their ages ranged from 3 years to 20 years (median: 13 years). The modal age for girls was 16 years and for boys 12 years. Fifteen $(7 \%)$ had new onset $\mathrm{CDH}$. The remainder had had recurrent $\mathrm{HA}$ for 2 months 
to 15 years (median: 2 years) before transformation to $\mathrm{CDH}$. The duration of $\mathrm{CDH}$ ranged from 1 month to 5 years (median: 6 months). The main HA types were : (i) Migraine: 11 (6\%), (ii) Tension-type (TT): 93 (47\%), and comorbid migraine and TT: 72 (37\%). Analgesia-overuse occurred in 4. Stressors were identified in 82 $(42 \%)$, anxiety disorder in $3(7 \%)$, and depression in $17(9 \%)$. Seven (4\%) had severe disabling CDH.One hundred and seventy-nine (91\%) were headache free or greatly improved, 91 of them $(51 \%)$ without specific drug treatment. Forty-nine $(25 \%)$ were also seen by a psychiatrist.

Conclusions CDH is a common HA disorder in children and adolescents, especially in teenage girls. A prospective neuropsychiatric approach is needed for evidenced-based management.

\section{0-18 CHRONIC DAILY HEADACHE IN ADOLESCENCE}

M.S. Smith

Department of Pediatrics, University of Washington. Seattle, WA, USA, e-mail:sseshia@sasktel.net

Background This study compares clinical, psychological, functional and individual characteristics of adolescents with chronic daily headache $(\mathrm{CDH})$ with recurrent pediatric headache $(\mathrm{RPH})$.

Methods 336 patients with a mean age of $13.3 \pm 2.1$ in a behavioral treatment program were categorized as $\mathrm{CDH}(\geq 4$ days/week) or RPH $(<4$ days/week). Self-report data included: Spielberger State-Trait Anxiety Inventory-Trait, Children's Depression Inventory, Childhood Somatization Inventory, Illness Attribution Questionaire, perceived self-efficacy, school days missed, functional impact, and cold pressor testing.

Results Compared with $\mathrm{RPH}$, adolescents with $\mathrm{CDH}$ were older $(p<0.001)$, more likely female $(p<0.05)$, less likely to meet criteria for migraine $(p<0.05)$, report longer duration of headache episodes $(p<0.01)$, miss more school due to headache $(p<0.05)$, and have a lower sense of self-efficacy regarding headache control $(p<0.01)$. Parents of $\mathrm{CDH}$ patients were more likely to attribute their child's headache to constitutional or environmental causes. There were no significant group differences for anxiety, depression, somatization, perceived functional impact or cold pressor scores.

Conclusions This study indicates that adolescents with $\mathrm{CDH}$ are older and more likely to be female than those with RPH.The study provides no support for theories that adolescents with $\mathrm{CDH}$ have more psychological symptoms or increased pain sensitivity than adolescents with RPH.

\section{0-19}

\section{PREVALENCE AND FEATURES OF CHRONIC MIGRAINE IN CHILDREN: THE PERIOD 1993-1995 VERSUS THE PERI- OD 2001-2003. A CLAIM FOR AID}

M. Nicolodi, F. Sicuteri, A. Torrini

Interuniversity Headache Centre, Foundation for the Prevention and Therapy of Primary Pain and Headache, Florence, Italy; e-mail: m.nicolodi@email.it

Since 1988 we developed a methodology to distinguish chronic headache sub-groups. Criteria resemble the ones presented in Rome.

1993-1995 Versus 1000 headache sufferers, 1 child met the criteria for chronic migraine and 4 suffered from chronic paroxysmal hemicrania. They had hystory of episodic headache. Fifteen children matched for sex, age and social level were the controls. Two patients had family troubles. Patients and 1 control had school-life problems. Wang and Zung tests (cut off $=40$ ) indicated psychological troubles in the patients. CBLC and Conner's scale indicate normal scores for patients and controls, Parental Bonding Instrument (PBI) indicated overprotection; the same outcome regarded 5 controls.
2001-2003 Versus 1000 adult headache sufferers, 42 children suffered from chronic migraine, 5 from chronic tension-type headache and 5 from chronic paroxysmal hemicrania. All the patients have history of episodic headache. Family problems characterized 7 children (4 migraineours, 3 tension-type headache suffers). In a control group of 40 exempts, matched for age, sex and social level, 7 have the same problems. Patients and 5 controls had poor peer-related performances and mood disturbances. PBI indicated overprotection in 14 patients and 9 controls. Twelve patients and 2 controls had antisocial behaviour (CBLC, Conners' scale). It was evident an increase $(p<0.001)$ of chronic headache in childhood associated to increase $(p>0.01)$ in antisocial behaviour.

\section{0-20}

\section{PROGNOSIS OF MIGRAINE AND TENSION-TYPE HEADACHE IN CHILDREN AND ADOLESCENTS}

$C$. Kienbacher $C$. Wöber, K. Zebenholzer A. Karwautz J. Geldner, H.E. Zesch, A. Hafferl-Gattermayer, Ç. Wöber-Bingöl

Headache Unit, Department of Neuropsychiatry of Childhood and Adolescents, Medical University of Vienna, Vienna, Austria; e-mail: christian.kienbacher@univie.ac.at

The aim of this study was to examine the prognosis of migraine and tension-type headache (TTH) in children and adolescents and to clarify whether the baseline data of patients who become headache-free lateron differ from those with persisting headaches. We examined 227 children referred to a tertiary care center and performed a semistructured interview at the time of the first visit and $6.6+1.6$ years afterwards. For comparing the baseline data of patients with and without headache at follow-up we calculated Mann-Whitney-tests and Chi-square tests, respectively. At baseline, 140 patients had migraine and 87 had TTH. At follow-up, 69 patients $(30 \%)$ were headache-free for at least one year, and $158(70 \%)$ still suffered from headache. The time between onset of headache and the first visit was significantly shorter in patients who became headache-free than in those with persisting headache (median, 18 vs. 24 months; $p=0.016$ ). All other baseline data, i.e. patient age, frequency, duration and intensity of headache, aggravation of pain by physical activity, nausea, vomiting, photophobia, phonophobia and aura symptoms, as well as the headache diagnosis, did not differ in the two groups. In conclusion, the probability of becoming headache-free for at least one year is inversely related to the time since onset of headache. Accordingly, early intervention seems to be an essential prognostic factor in children and adolescents with migraine and tension-type headache.

\section{0-21}

\section{THE USE OF INTRA-ORAL SPLINTS IN THE TREATMENT OF MIGRAINE IN CHILDREN AND ADOLESCENTS} E. Shevel

The Headache Clinic, Johannesburg, South Africa; e-mail: drshevel@headclin.com

Previous studies have shown that inter-occlusal splints can be effective in the treatment of migraine. This retrospective study investigated the effect of treatment a palatal non-occluding splint on 16 migraineurs between the ages of 9 and 16. Subjective telephonic assessments were carried out on 9 females and 7 males. A further 7 females and 4 males were either lost to follow up, or did not complete treatment. Subjective assessment by the patients was that the majority experienced considerable reduction in frequency and severity of their migraine pain and associated symptoms while wearing the appliance. It was concluded that a non-occluding palatal splint is of value in the preventative treatment of migraine in children and adolescents. 


\section{0-22}

\section{RANDOMIZED, DOUBLE-BLIND, PLACEBO-CONTROLLED} STUDIES OF SUMATRIPTAN NASAL SPRAY (SNS) IN ADOLESCENT MIGRAINEURS

${ }^{I}$ P. Winner, ${ }^{2}$ D. Rothner, ${ }^{3}$ C.J. Webster, ${ }^{3}$ P. Barrett

${ }^{1}$ West Palm Beach, Florida, USA; ${ }^{1}$ Cleveland, Ohio, USA;

${ }^{3}$ GlaxoSmithKline, North Carolina, USA; e-mail: pwinner777@aol.com

Objective To compare efficacy and tolerability of SNS (Study 1: 5, 10, $20 \mathrm{mg}$; Study 2: 5, $20 \mathrm{mg}$ ) to placebo in acute treatment of migraine in adolescence.

Design and methods 2 randomized, placebo-controlled, double-blind studies were conducted in adolescents with at least a 6-month history of migraine. Subjects self-treated a single moderate or severe attack. The primary endpoint for Study 1 was percentage of subjects with headache relief (HR) at 2-hours post-dose; for Study 2, HR at 1-hour post-dose and sustained relief (SR) from 1 to 24 hours. Secondary endpoints included HR at other time points and presence of associated symptoms. Results Study 1 has been previously published (Winner, Pediatrics, 2000). In Study 2, 738 subjects (mean age, 14 years) completed the study. SNS $20 \mathrm{mg}$ provided greater HR than placebo at $30 \mathrm{~min}(42 \%$ vs. $33 \%, p=0.046), 1$ hour ( $61 \%$ vs. $52 \%, p=0.087)$, and 2 hours $(68 \%$ vs. $58 \%, p=0.025)$ post-dose. SNS $20 \mathrm{mg}$ provided greater SR than placebo $(41 \%$ vs. $32 \%, p=0.061)$. Significant differences $(p<0.05)$ in favor of SNS $20 \mathrm{mg}$ over placebo were observed for several secondary endpoints. SNS $5 \mathrm{mg}$ was generally more effective than placebo but the differences did not reach statistical significance. Pooled results of both studies showed a greater HR with SNS $20 \mathrm{mg}$ at $30 \mathrm{~min}(p=0.016), 1$ hour $(p=0.007)$, and 2 hours $(p=0.005)$ postdose compared with placebo. Both doses of SNS were well tolerated.

Conclusions SNS is effective and well tolerated in the treatment of acute migraine in adolescents. 


\section{POSTER PRESENTATIONS}

\section{EPIDEMIOLOGY}

\section{P-01 \\ SECULAR LONG-TERM TRENDS IN HEADACHE OCCUR- RENCE IN SCHOOLCHILDREN}

${ }^{I} P$. Anttila, ${ }^{2}$ L. Metsähonkala, ${ }^{2,3}$ M. Sillanpää

${ }^{1}$ Child and Adolescent Health Care Unit; ${ }^{2}$ Turku City Hospital, Departments of Child Neurology; ${ }^{3}$ Public Health, University of Turku, Turku, Finland; e-mail: pirjoa.anttila@pp.fimnet.fi

Background To study changes in time of the occurrence of headache in schoolchildren during 1974-2002.

Patients and methods A population-based study on migraine and other headaches, carried out in 1974 in children starting school in Turku, was repeated in 1992 and 2002 using the identical study design, with the same schools, age groups, time of year and the same data collection method. The final study population included 1927 7-year-old children in 1974, 1436 children in 1992 and 1066 children in 2002. The response rates were $90 \%, 96 \%$ and $81 \%$, respectively.

Results The prevalence of present overall headache (during the preceding 6 months) had significantly increased over time from $14.4 \%$ in 1974 to $51.5 \%$ in 1992 and up to $63.3 \%$ in $2002(p<0.0001)$. Also frequent headache ( $>1$ per month) had increased from $4.7 \%$ in 1974 to $11.7 \%$ in 1992 and up to $19 \%$ in $2002(p<0.0001)$. Similarly, the prevalence of migraine had increased from $1.9 \%$ in 1974 to $5.7 \%$ in 1992 and up to $9.2 \%$ in $2002(p<0.0001)$.

Conclusions Increase over time in headache prevalence in schoolchildren continues to occur. Reasons for this development will be discussed.

\section{P-02}

\section{THE PREVALENCE AND CHARACTERISTICS OF HEADACHE} IN SCHOOLCHILDREN

${ }^{1} R$. Bugdayci, ${ }^{2} A$. Özge, ${ }^{1}$ T. Sasmaz, ${ }^{1}$ Ö. Kurt, ${ }^{2} H$. Kaleagasi, ${ }^{2} A$. Karakelle, ${ }^{1} H$. Tezcan, ${ }^{2}$ A. Siva

${ }^{I}$ Neurology and ${ }^{2}$ Public Health Departments, Mersin and Istanbul Universities, Turkey; e-mail:aozge@mersin.edu.tr

Background This cross-sectional, selective (ranging from 2 nd to 5 th grades) study was conducted to determine the prevalence of recurrent headaches in school children in Mersin city of Turkey.

Methods A stratified sample of 5.777 students was selected to be representative of the city's school children population. Data was obtained in two steps: firstly a pair of structured questionnaires was designed to evaluate the presence and clinical features of recurrent headaches, both in children and their parents. Secondly, each child reported to have headache was interviewed individually. After the data quality control process, study sample was reduced to 5.562 children.

Results The prevalence of recurrent headache was $49.2 \%$ (2.739 of $5.562)$ and the prevalence of current headache was $31.3 \%$ (859 of 2.739 ) in this study. Among the studied population $24.7 \%$ had tension type headache, $10.4 \%$ had migraine. Girls had significantly more frequent headache than boys. The regression analysis revealed as increasing age, female gender, low socio-economic status of family, low education level of mother, and positive family history of headache. Additionally, having travel sickness had a statistically significant effect on school children headache.

Conclusions It was concluded that, headache is a common health problem among school children, which merits increased attention detailed with various multi-centre and clinical studies.

\section{P-03} HEADACHE IN A PEDIATRIC NEUROLOGY DEPARTMENT

I. Carrilho, M.A. Castilho, J. Guerra

Department of Pediatric Neurology, Hospital Maria Pia, Porto, Portugal; e-mail: neurop@hmariapia.min-saude.pt

Purpose Classify the headache in a group of patients followed in a Paediatric Neurology Department and analyse the investigation and preventive therapy they have done.

Materials and methods Retrospective evaluation of the medical records of children followed in a headache consultation, with recurrent headache, between January 2000 and December 2002. The type of headaches was redefined according to the International Headache Society diagnostic criteria (1988). Preventive therapy was used in children with more than two attacks per month with impact on individual life. Results A total of 128 patients were identified (74 female and 54 male). The age at the first episode ranged between 2 and 16 years (mean 8.5 years). Headaches were classified as: migraine - 39\%, two forms of headache (migraine and tension-type) - $28 \%$; tension - $23 \%$; other type - $10 \%$. Imaging studies were done in 51 patients $(39 \%)$ and EEG in 18 (14\%). Preventive therapy was initiated in 50 of the 83 patients with migraine $(60 \%)$. We have a good response in $86 \%$ of them with a follow-up time of 19 month.

Discussion Migraine was the most frequent type of headache. Imaging studies and prophylactic medication were done in a high percentage of children. The specific population we have study could explain this.

\section{P-04}

CHANGES IN HEADACHE FREQUENCY IN ADOLESCENCE PROSPECTIVE THREE YEAR STUDY

${ }_{1,3}^{3}$ K. Laimi, ${ }^{2}$ L. Metsähonkala, ${ }^{4}$ P. Anttila ${ }^{1}$ M. Aromaa ${ }^{3}$ J.J Salminen, 1,2M. Sillanpää

Departments of ${ }^{1}$ Public Health, ${ }^{2}$ Child Neurology, ${ }^{3}$ Physical Medicine and Rehabilitation, University of Turku, Child and Adolescent Health Care; ${ }^{4}$ Turku City Hospital, Turku, Finland; e-mail: katri.laimi@utu.fi

Background The objective of the study was to examine factors which might contribute to an increase or decrease in headache frequency from the age of 13 to 16 years.

Patients and methods A population-based prospective study comprising a screening questionnaire at the age of $12(n=1409$, response rate $81 \%$ ) followed, at the age of 13 years, by interview and clinical examination of randomly selected 311 children from different headache subgroups classified according to the IHS classification, and adolescents with no headache. Finally, at the age of 16 years, 228 (73\%)/ 311 adolescents could be re-examined.

Results Headache increased clinically significantly in $22 \%(29 \%$ of girls and $14 \%$ of boys) and decreased in $17 \%$ (12\% of girls and $23 \%$ of boys). The frequency of migraine tended to rise more than that of tension-type headache. The analysis of other possible explanatory factors is underway and will be presented.

Conclusions Headache and migraine in particular, increases in girls but decreases in boys in adolescence.

\section{P-05}

THE AGE AND SEX DEPENDENT DISTRIBUTION OF ONEYEAR HEADACHE PREVALENCE AND HEADACHE CHARACTERISTICS OF SCHOOLCHILDREN IN MERSIN

${ }^{1}$ A. Özge, ${ }^{2}$ R. Bugdayci, ${ }^{2}$ T. Sasmaz, ${ }^{I}$ A. Karakelle, ${ }^{1} H$. Kaleagasi, ${ }^{2} \ddot{O}$ Kurt, ${ }^{2}$ H. Tezcan, ${ }^{1}$ A. Siva

${ }^{1}$ Neurology and ${ }^{2}$ Public Health Departments, Mersin and Istanbul Universities, Turkey; e-mail: aozge@mersin.edu.tr

Background The objective of this study is to determine age and sex distribution of headache prevalence and headache characteristics of schoolchildren in Mersin.

Methods The stratified sample was composed of 5.562 children 
Results The prevalence of recurrent headache was $49.2 \%$ and the prevalence of current headache was $31.3 \%$. TTH was more common than migraine ( $24.7 \%$ versus $10.4 \%)$. The prevalence distribution of headache by age and sex showed a peak in the female population at the age of 11 $(27.2 \%)$ with a plateau in the following years. The prevalence of headache for girls significantly increased in children with 8,9 and 10 year-olds and the figures of girls were grater than boys. On the other hand, at the age of 12 year olds, boys suffered from headache insignificantly more common than girls. Logistic regression analysis showed that, with the increasing age, being first children of the family, having a crowded family, having a dying siblings, and increased mother's age had a significant effect on occurrence of headache in each age group. Also, throbbing quality of pain and mother's headache has an important effect on lower age groups. It was striking that, siblings headache history 6.2 fold increased the ratio of headache in pupils with 9 ages compared to 8 year-olds.

Conclusions It was concluded that, there was a gradual increase of headache with age. Also girls had significantly more frequent headache than boys.

\section{P-06 \\ CHRONIC/RECURRENT HEADACHE AMONG STUDENTS IN A BULGARIAN SCHOOL}

\section{Pacheva}

Departments of Pediatrics and Medical Genetics, Medical University,

Plovdiv, Bulgaria; e-mail: inapatcheva@hotmail.com

Background The aim of the study was:

- to establish the occurrence of chronic/ recurrent headache among students in one school;

- to classify the headache;

- to reveal some differences, considering sex and age;

- to analyze the used therapeutic approach.

Materials and methods 530 children from all classes, aged 7-18 years, were included. Either children above 10 years or their parents filled the headache questionnaire. The diagnosis was based on the filled questionnaire, patient's interview, physical and neurological examination, some additional investigations. The headache was classified according to the last International Classification of headache with revisions for pediatric age.

Results $34.53 \%$ of students suffered from headache $-42.96 \%$ of girls and $25.30 \%$ of boys. The distribution of headache was: $38.80 \%$ tension type/TTH $37.16 \%$ - migraine, $1.09 \%$ primary stabbing, $0.55 \%$ primary exertional, $10.38 \%$ - either probable migraine or probable TTH, $4.37 \%$ - mixed, $1.09 \%$ - secondary, $6.56 \%$ - unclassified. TTH prevailed by the age of 10 , after this age migraine prevailed. 55 of 183 students had looked for medical attention, but 123 had taken medication. Conclusions More than a third of the students suffered from headache. Most students took medication without medical consultation. Headache increased with age. Migraine and TTH occur nearly evenly. Other headaches were rare. Female sex prevailed. Headache, covering both-probable Migraine or TTH points the need for more revisions to pediatric diagnostic criteria.

\section{P-07} COMPARATIVE ASPECTS OF HEADACHE PREVALENCE IN
SCHOOLCHILDREN OF RIGA (LATVIA) AND LIVERPOOL (UK)

I. Purina, D. Jegere, R.K. Sinha

Lativa Maritime Hospital, Latvia; e-mail: jegere@ljmc.lv

Background The aim of the investigation was to detect the incidence of headache, sex, age relations, risk factors and point out the possible clinical forms of children's headache in two populations of Riga (Latvia) and Liverpool (UK).

Materials and methods The investigation was carried out in schools by questioning 1.015 children of Riga and 1.225 in Liverpool aged 6-18 years.
Results The incidence of headache among schoolchildren was high in both countries with prevalence in Riga $(81 \%)$ in comparison with Liverpool - 68\%. There was increase of headache with age for both sexes till 9 years in Liverpool group and 13 years in Riga group and decrease for boys after this age. Girls have remarkable prevalence in headache. $10.5 \%$ of Liverpool children and $6.5 \%$ of Latvia children fulfilled migraine criteria with remarkable prevalence for girls. Stress was a main risk factor for headaches in $78 \%$ of children and out of them $3.9 \%$ goes to migraine attacks. Only $30 \%$ of headache suffering children of Liverpool and $18 \%$ of Riga were consulted by doctor in the past year. Headache form was diagnosed only in $35 \%$ cases. Upon the treatment with medication there was a definite advantage $(86.7 \%)$ for children with different headache forms.

Conclusions Headache is frequent symptom among schoolchildren. The incidence of headache in schoolchildren in two populations differ. There is a relation between incidence of headache in age and sex aspect with a definite prevalence for girls at the age of puberty.

\section{P-08 \\ CHANGES IN THE CHARACTERISTICS OF CHILDHOOD HEADACHE FROM PRESCHOOL AGE TO PREPUBERTY: A CONTROLLED CLINICAL STUDY \\ ${ }^{I}$. Virtanen, ${ }^{I}$ M. Aromaa, ${ }^{I}$ P. Rautava, ${ }^{2}$ L. Metsähonkala, ${ }^{I}$ P. Anttila,} ${ }^{3} \mathrm{H}$. Helenius, ${ }^{2} \mathrm{M}$. Sillanpää

${ }^{I}$ Department of Public Health; ${ }^{2}$ Department of Pediatric Neurology; ${ }^{3}$ Department of Biostatistics, University of Turku, Finland; e-mail: ruut.virtanen@utu.fi

Background We studied changes in the occurrence of different headaches and related factors among Finnish children in a prospective setting. Patients and methods A questionnaire was sent to 1132 families of six-year-old children. A clinical examination was performed to 96 sixyears-old children with primary headache (preceding 6 months) and to their pairwise matched non-headache controls. Six years later, at age of 12 , the same children $(n=85,88 \%)$ and their controls $(n=85,88 \%)$ were clinically re-examined.

Results During follow-up, 18(15.3\%)/85 children became totally headache-free, $5(4.3 \%) / 85$ begun to suffer from migraine and 7(6.0\%)/85 from tension-type headache. $18(33.3 \%) / 54$, classified as migraine at age 6 , had turned to tension-type headache, whereas $13(36.1 \%)$ of 36 children with tension-type headache had changed into migraine. Concurrent symptoms such as restlessness $(\mathrm{OR}=0.2 ; 0.06-0.77)$, flush $(\mathrm{OR}=0.1$; $0.003-0.80)$ and abdominal symptoms $(\mathrm{OR}=0.2 ; 0.04-0.51)$ became less marked, while odorphobia $(\mathrm{OR}=4.8 ; 1.79-16.11)$, dizziness $(\mathrm{OR}=3.4 ; 1.43-9.42)$ and balance disturbances $(\mathrm{OR}=4.7 ; 1.30-25.32)$ became more typical at age 12 . Hunger $(\mathrm{OR}=2.6 ; 1.13-6.27)$ triggered more often headache at prepuberty than at preschool age.

Conclusions At arrival of prepuberty neurological symptoms, especially vertigo and balance disturbances, seem to be linked to the change in characterization of headache.

\section{CLASSIFICATION}

\section{P-09 \\ TENSION TYPE HEADACHES OR EARLY MIGRAINES IN CHILDREN AND ADOLESCENTS. A MODIFICATION TO IHS 2 (TENSION TYPE HEADACHES) DIAGNOSTIC CRITERIA \\ M.V. Francis}

Headache and Migraine Research Centre Cherthala, India; e-mail: mvfrancis@rediffmail.com

Objective To study whether or not the current IHS criteria for tension type headaches are appropriate for children and adolescents. To document early paediatric migraine features and to suggest a modification to IHS 2 diagnostic criteria. 
Design 516 children and adolescents aged 5 to 15 years were diagnosed as IHS 2 (2.1 and 2.3) on their first consultation were identified when they later presented with headpain with migraine features All the symptoms and other associated features of initial and final presentations were retrospectively analysed. All the triggers precipitating these pain attacks also were noted. Patients with nausea, vomiting and near daily headaches (more than 15 episodes in one month for 6 months suggestive of chronic tension type headaches) were excluded from the study.

Results IHS 2.1 were diagnosed in 347 patients (minimum 10 episodes and 30 minutes duration, bilateral, non throbbing, mostly activity not affected), IHS 2.3 in 169 patients (less than 10 episodes, non throbbing, bilateral, mostly activity not affected), 328 of these patients reported definite phonophobia or questionable phonophobia photophobia without phonophobia by 57. During the follow-up period of 2 to 6 years IHS migraine was diagnosed in 36 more than 2 hours duration, IHS R in 248 more than one hour, IHS RR 2001 modified brief migraines, duration less than one hour in 232 .

\section{P-10 \\ IHS 1.7 (MIGRAINOUS DISORDER) OR IHS RR 2001 MOD- IFIED: A ONE YEAR STUDY}

\section{M.V. Francis}

Headache and Migraine Research Centre Cherthala, India, e-mail: mvfrancis@rediffmail.com

Objective To differentiate between IHS 1.7 (migrainous disorder with and without aura) and IHS RR 2001 Modified in children and adolescents.

Methods and results 204 children and adolescents aged 5 to 15 years were diagnosed as IHS 1.7 (migraine with and without aura) during 1996 and 2001 (less than 5 episodes of activity affected (moderate to severe) headpain lasting more than an hour or more than 5 episodes lasting less than an hour with only phonophobia or photophobia as one of the autonomic symptom reported without nausea or vomiting). On follow-up during 2001 and 2002, the diagnosis was changed as either IHS R or IHS RR 2001 modified (recurrent activity affected attacks (motionless), upto or less than 1 hour duration, one autonomic symptom, one common migraine trigger precipitating the attacks and one migraine parent.

Conclusions If common migraine triggers (other than tension anxiety situations) and family history (one migraine parent or sibling) can be included in IHS 1.7 for migraine without aura, most of them can be diagnosed as IHS RR 2001 modified or IHS R on first presentation itself. Common migraine triggers precipitating the attacks, activity getting affected and one migraine parent or sibling differentiates this from tension anxiety headaches. It is always better to diagnose migraine rather than migrainous disorder on first consult.

\section{P-11}

\section{CRITICAL ANALYSIS OF DIAGNOSTIC CRITERIA FOR HEADACHE IN CHILDREN AND ADOLESCENTS}

M.M.F. Lima, N.A.M.R. Padula, L.C.A. Santos, L.D.B. Oliveira, S. Agapejev

Department of Neurology-Psychiatry, Medical School, UNESP, Botucatu SP, Brazil; e-mail: martinsemarcia@uol.com.br

Background The widely used criteria of the International Headache Society (IHS) 1988 to define migraine without aura in children are highly specific but show poor sensitivity, with a larger percentage of headaches being classified as migranous disorder. The new classification of the IHS 2003 included a reduction in the required duration of episodes from $1 \mathrm{~h}$ to 72 hours and bilateral pain for migraine in children and adolescents. Until the moment there isn't in the literature as far as the authors are concerned studies comparing both of them. The present study analize the IHS 1988 and IHS 2003 diagnostic criteria in children and adolescents.

Patients and methods 496 patients of the Headache outpatient ward for children and adolescents were retrospectively studied from 1992-2002, using the intuitive clinical diagnosis (gold standard). The IHS 1988 and IHS 2003 criteria were statistically compared according to: Sensitivity (S), Specificity (Sp), Positive Predictive Value (PPV), Negative Predictive Value (NPV), according to formulas/criteria: CLAO-PAHO/WHO -1988 and of Rouquayrol (1993).

Results IHS 1988 criteria showed $\mathrm{S}=21, \mathrm{Sp}=100, \mathrm{PPV}=100, \mathrm{NPV}=53$ for migraine without aura and IHS 2003 criteria showed $S=53$, $\mathrm{Sp}=100, \mathrm{PPV}=100, \mathrm{NPV}=66$, when compared with the gold standard. Conclusions The IHS 2003 criteria showed greater sensitivity and high specificity for migraine than IHS 1988. The criteria duration and location of pain may explain the greater sensitivity of the IHS 2003 criteria.

\section{P-12}

CLASSIFICATION OF CHILDHOOD HEADACHES AND EVALUATION OF DEPRESSION, ANXIETY AND SELF RESPECT SCALES

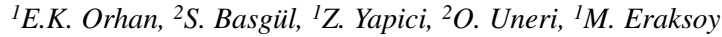

${ }^{1}$ Department of Neurology, Faculty of Medicine, Istanbul University, Turkey; ${ }^{2}$ Department of Child Psychiatry, Faculty of Medicine, University of Kocaeli, Istanbul, Turkey; e-mail: senembasgul@yahoo.com

Background The criteria for headache of the International Headache Society (IHS) currently used in diagnosis of headaches, though revised, are not likely as useful in children and adolescents as in adults. Depression and anxiety disorders can be seen commonly in children with headaches. The purpose of our study was to classify the children with headaches according to the criteria, and to determine the levels of anxiety and depression in these children as well as to evaluate their self respect.

Patients and methods Sixtythree patients from 191 records were reevaluated according to the criteria, sociodemographic variables, school status and family history. The Children's Depression Inventory (CDI), State-Trait Anxiety Inventory For Children (S-TAIC), Cooper-Smith Self-Esteem Inventory (SEI) and Piers-Harris Children's Self Concept Scale (CSCS) were applied and scored for 55 of these patients.

Results Thirty-eight of the 63 patients were female (60\%) and 25 were male $(39 \%)$. Mean age was $12.6 \pm 3.3$. There were $3(4.7 \%)$ migraine with aura, 29(46\%) migraine without aura, $11(17 \%)$ tension type headache, 2 (3\%) post-traumatic headache, and 1 (1.6\%) mixed type headache. Our 17 children (27\%) did not meet the criteria revised according to some recent reports. In children with headache, the followings found over limit points; 6 (10\%) of CDI, $10(18 \%)$ of SAIC, $16(29 \%)$ of TAIC. No significant correlation could be found between headache types and scales.

\section{P-13}

IDIOPATHIC STABBING HEADACHE, EXTERNAL COMPRESSION HEADACHE, ICE-CREAM HEADACHE, BENIGN COUGH HEADACHE AND BENIGN EXERTIONAL HEADACHE IN CHILDREN

N. Senbil, Y. Gürer, S. Ücler, L. Inan

Dr. Sami Ulus Children's Hospital; Ankara State Hospital, Ankara, Turkey; e-mail: senbilon@ttnet.net.tr

Aim To evaluate the frequency of idiopathic stabbing headache (HA), external compression HA, HA associated with the ingestion of a cold stimulus (ice-cream HA), benign cough HA and benign exertional HA (IHS 4) in children and adolescents with migraine or tension-type headache (TTH). 
Methods We examined 175 patients (91 girls, 84 boys, aged 5 to 16 years) suffering from migraine or TTH and applied a questionnaire covering the IHS criteria of the headaches mentioned above. If the patients had cough headache, cranial imaging was performed routinely.

Results Of 175 patients with migraine or TTH, 84 (48\%) had in addition at least one of the headaches listed in IHS 4. Benign exertional HA was found in $39.3 \%$ of the patients and ice cream HA in $35.7 \%$. The other headache types were detected in $10.7 \%-16.6 \%$. The prevalence of IHS 4 headaches did not differ between patients with migraine $(x \%)$ and TTH $(y \%)$. Twenty patients (11 with idiopathic stabbing headache, 5 with benign exertional headache, and 4 with ice- cream headache) rated the IHS 4 headache as the chief complaint although they also had migraine or TTH.

Conclusions Almost 50 of the children and adolescents referred for migraine or TTH suffer from additional primary headaches listed in IHS 4. Benign exertional HA and ice cream HA are most important. In some patients, the IHS 4 headache seems to have more impact than migraine or TTH.

\section{P-14 \\ OVERLAPPING FEATURES OF MIGRAINE AND EPISODIC TENSION-TYPE HEADACHE: RESULTS OF AN EPIDEMIO- LOGICAL STUDY IN SCHOOL AGED CHILDREN \\ ${ }^{1} D$. Turkdogan, ${ }^{2} S$. Cagirici, ${ }^{3} D$. Soylemez, ${ }^{2} U$. Turk \\ ${ }^{I}$ Institute of Neurological Science, Marmara University, Istanbul; ${ }^{2}$ Department of Neurology, Kartal State Hospital, Istanbul; ${ }^{3}$ Department of Biostatistics, Marmara University Istanbul, Turkey; $e$ - mail:dturkdogan@hotmail.com}

Background In daily practice, the presence of various common features in patients with migraine and ETTH makes difficult to distinguish from one another. Moreover, previous studies assessed challenging features in differential diagnosis based on the 1988 IHS criteria, which have been proved to be less sensitive in pediatric population.

Objectives We conducted this epidemiological survey to investigate: 1) prevalence of ETTH and migraine diagnosed based on revised IHS criteria proposed by Winner et al. (1997); 2) overlapping features of both headache types.

Patients and methods A detailed questionnaire inquiring characteristic features of primary headache syndromes mandatory for classification was administered in 483 ( $57 \%$ female) of 2.504 children aged 10 to 17 years. Results The prevalence for migraine was $8.2 \%$ and for ETTH, 5\%. Out of 208 children with migraine, 107 (51\%) reported ETTH-type symptoms and $65(52 \%)$ of 126 children with ETTH reported migrainetype symptoms. The presence of pressing pain $(46 \%)$ and lack of aggravation of pain by physical activity $(61 \%)$ were the major ETTH features in patients with migraine. Throbbing pain $(82 \%)$ and aggravation by physical activity (39\%) determined migraine features in patients with ETTH. The common precipitating factors were excitement, caffeine, watching TV and coming back to school after a holiday.

Conclusions The frequent co-occurrence of migraine and ETTH symptoms is in favor of the presence of a common pathogenesis.

\section{P-15 \\ CONVENTIONAL VERSUS RESTRICTIVE CRITERIA OF TEN- SION-TYPE HEADACHE IN CHILDREN AND ADOLES- CENTS: A LONGITUDINAL STUDY}

C. Wöber, C. Kienbacher, K. Zebenholzer, A. Karwautz, J. Geldner, C. Wöber-Bingöl

Headache Unit, Department of Neuropsychiatry of Childhood and Adolescents, Medical University of Vienna, Vienna, Austria; e-mail: christian.woeber@univie.ac.at

Background The 2nd edition of the International Classification of Headache Disorders (ICHD-II) includes a proposal for more restrictive criteria of TTH. According to this proposal, at least 3 pain characteristics must be present and associated symptoms must be entirely absent with the exception of anorexia. The aim of this study was to apply conventional (C) and restrictive (R) criteria of TTH in children and adolescents and to examine whether the long-term course differs in these two groups. Methods We examined 227 children referred to a tertiary care center and performed a follow-up examination $6.6+1.6$ years after the first visit. All diagnosis were established post hoc according to ICHD-II applying TTH-C as well as TTH-R criteria.

Results At baseline, 140 patients had migraine and 87 had TTH. Fiftyfive percent of the latter fulfilled the criteria of TTH-R and $45 \%$ did not. At follow-up, 69 patients $(30 \%)$ were headache-free for at least one year, 105 patients $(46 \%)$ remained in the same diagnostic group and $53(24 \%)$ had shifted from migraine to TTH or vice versa. Among 36 patients who evolved from migraine to TTH, 50\% evolved to TTH$\mathrm{R}$ and $50 \%$ to TTH-C. In the patients who evolved from TTH to migraine $(n=17)$, the initial diagnosis was TTH-R in $65 \%$ and TTH-C in $35 \%$.

Conclusions The TTH-R criteria reduce the sensitity for TTH by almost 50\%. The long-term course does not differ between TTH-R and TTH-C in children and adolescents referred to a headache center.

\section{P-15A \\ 2004 IHS CRITERIA AND PAEDIATRIC PRIMARY HEADACHES}

L. Savi, P. De Martino, R. Lo Giudice, L. Pinessi

Department of Neurosciences, Headache Center, University of Turin, Molinette Hospital, Turin, Italy; e-mail: lsavi@molinette.piemonte.it

The optimal criteria for the diagnosis of primary headaches, in particular migraine without aura (MO) in children and adolescents have always been controversial. According to the 1988 IHS criteria a shorter headache duration was allowed for patients under 15 years ( 2 to 48 hours) while for those aged 15 years or over the same duration of attacks than adults was necessary (4 to 72 hours). In the past some Authors proposed a revision to the IHS criteria for paediatric MO mostly on the basis of data obtained using semi-structured interviews and clinical findings. In the newly published 2004 HIS criteria, such needs found an answer, and some special notes were defined, with the aim of better identify the illness characteristics in children and adolescents. To find out if a larger number of primary headaches, mainly MO, might be identified, thanks to the new criteria, we decided to study a group of 150 patients (age range 4-18 years) suffering from these types of headaches and already attending to the Headache Center of the University of Turin. So far, a group of 66 patients (46 females and 20 males, age range $8-18$ years, mean age \pm ES $15.09 \pm 0.43$ years) suffering from primary headaches and attending to the Headache Center of the University of Turin was evaluated. Intensity, duration, location of headache, quality of pain, influence of physical activity and the occurrence of concomitant features were taken into consideration. On the basis of these data $6(9.09 \%)$ subjects did not fulfil 1988 IHS criteria for MO, for the duration of the headaches attacks, that was less than two hours in all the cases. In 2 of them it was 1 hour, so they fulfilled the 2004 IHS criteria, while in the remaining 4 it was less than 1 hour. In conclusion, on our opinion the 2004 IHS criteria seem to be better than the oldest ones to diagnose migraine headaches in children and adolescents, even if the duration of the headache attack should be probably further reduced.

\section{GeNeTIC ASPECTS AND PATHOPHYSIOLOGY}

\section{P-16}

GENETIC ASSOCIATION STUDY OF THE SEROTONERGIC SYSTEM IN PEDIATRIC MIGRAINE

1, ${ }^{2} \mathrm{~K}$. Boór, ${ }^{1,2}{ }^{2}$. Szilágyi, ${ }^{3}$ I. Orosz, ${ }^{1} H$. Kalász, ${ }^{2}$ M. Sasvári-Székely, ${ }^{3}$ V. Farkas 
${ }^{1}$ Department of Pharm. and Pharmacotherapy; ${ }^{2}$ Department of Medical Chemistry, Molecular Biology and Pathobiochemistry; ${ }^{3}$ Department of Pediatrics, Semmelweis University, Budapest, Hungary; e-mail: boor@pharma.sote.hu

Migraine is a multifactorial disease with both environmental and genetic causative factors. The patomechanism of migraine is still not clear, however the role of the serotonergic system is widely accepted. Genetic association study was performed to investigate the prevalence of 3 polymorphisms in 2 candidate genes related to the serotonergic system. The cohort of 87 unrelated children was stratified according to migraine subtype (with or without aura) and the onset of disease $(<6$ years, respectively $>6$ years) in case-control study. Additionally 159 parents were involved in the family-based study (TDT). The control group consisted of 648 individuals. Three VNTR-s were analysed by PCR based method, one in the promoter region (5-HTTLPR) and one in intron 2 (STin2) of the serotonin transporter gene, and another in the monoamine-oxidase A gene. Khi2 and TDT khi2 tests were used for all statistical analyses. The 10 repeats containing allele (10x) of STin2 and also the 10x containing genotypes were less frequent in migraine with aura patients and the 10x allele was less frequently transmitted to the affected offspring. In case of the other analysed polymorphisms we found no significant association compared to the controls. Our results suggest that the 10x allele of STin2 can be a protective variant in migraine with aura that confirms the important role of the serotonin transporter in the patomechanism of migraine.

\section{P-17} CHANGES OF EXTEROCEPTIVE SUPPRESSION OF MAS-
SETER MUSCLE ACTIVITY IN CHILDREN'S AND ADOLES-
CENT'S MIGRAINE POINT TO BRAINSTEM HYPEREXCENT'S MY

\section{F. Ebinger, D. Rating}

Pediatric Hospital, Department of Pediatric Neurology, University of Heidelberg, Germany; e-mail: friedrich_ebinger@med.uni-heidelberg.de

Background In persons voluntarily closing the mouth, electrical or mechanical stimulation of the lower part of the face on either side elicits two successive transient suppression periods (ES1 and ES2) of the electromyographic activities (EMG) of the masseter and temporalis muscles bilaterally. ES2 was found to be reduced in adults with chronic tension-type headache by some investigators. Studies in patients with migraine would have normal results. To date, no studies in children and adolescents have been published.

Methods In 14 patients with migraine, six patients with episodic tension-type headache, ten patients with mixed headache, and in 19 controls between 6 and 18 years of age, we studied exteroceptive suppression of masseter muscle activity in the headache-free interval. It was registered based on the standards recommended by the European Headache Federation, modified for application in children. Stimulation site was the labial commissure.

Results While regarding ES1 no group differences were found, the EMG reactivation between ES1 and ES2 was shorter and ES2 was longer in the migraine group. In contrast, the patients with tension-type headache or mixed headache showed no significant modifications of ES2.

Conclusions These findings differ from the results in adults partly. They suggest hyperexcitability of central trigeminal neurons and impairment of antinociceptive brainstem systems in children and adolescents with migraine.

\section{P-18}

CHANGES OF AUTONOMIC REGULATION IN CHILDREN AND ADOLESCENTS SUFFERING FROM MIGRAINE

F. Ebinger, M. Kruse, D. Rating
Pediatric Hospital, Department of Pediatric Neurology, University of Heidelberg, Germany; e-mail: friedrich_ebinger@med.uni-heidelberg.de

Background In adult migraineurs, studies on autonomic regulation were interpreted as pointing to impaired sympathetic or parasympathetic function. In juvenile migraineurs, the few existing studies reported partly contradictory results.

Methods We studied autonomic regulation in the headache-free period in 70 children and adolescents with migraine by cardiorespiratory function tests. The control group consisted of 81 healthy subjects. Blood pressure was measured and heart rate variability analyzed in time and frequency domain during a resting period with spontaneous breathing, during metronomic breathing with various breathing frequencies, during two different orthostatic tests (tilt-table test and active standing), during Valsalva maneuver, and during isometric muscle activity (sustained handgrip).

Results At metronomic breathing heart rate variability was lower than in controls. In the tilt-table test we found an increased Ewing-ratio. In the youngest age group (6-9 years) we found a higher Valsalva-ratio. In patients with a longer history of migraine the increase of diastolic blood pressure during the tilt-table test was higher.

Conclusions These results suggest that juvenile patients with migraine show a restricted ability of their central autonomic network to rest in itself as well as hyperreagibility to external stimuli. Our findings support the concept of a migraine personality failing to relax and remaining in a state of tensed attention to external stimuli.

\section{P-19} PROGNOSES OF HEADACHES WITH EPILEPTIC EEG DIS-
CHARGES IN CHILDREN

${ }^{I}$ M. Fujita, ${ }^{2}$ J. Fujiwara, ${ }^{I}$ T. Maki, ${ }^{I}$ M. Shigeta, ${ }^{3}$ N. Isobe ${ }^{1}$ Department of Pediatrics, Tsukubagakuen Hospital; ${ }^{2}$ Department of Health Science, Health Science University; ${ }^{3}$ Department of Pediartics, Kandatsu Hospital, Tsukuba, Japan; e-mail: mitfujita@tulip.sannet.ne.jp

Background Severe and persistent headaches with epileptic EEG discharges without convulsions are occasionally recognized in children.

Patients and methods We classified the headaches of children with epileptic EEG discharges according to IHS criteria (1988). We also investigated foci of EEG abnormalities and the effect of treatment. The same children were followed-up for 5-13 years after their initial examination, and their prognoses were examined.

Results Of the 308 children with chronic and recurrent headaches, 19 (6\%) had severe and persistent headaches with epileptic EEG discharges. They had never experienced convulsion and impairment of consciousness. Out of 19 children, 8 were classified as migraine and 11 were as "headache not classifiable". Severe headaches completely disappeared in all cases after administration of anticonvulsants. However, $10(53 \%)$ have suffered from other types of mild or moderate headaches after 5-13 years. Conclusions Our study indicated that prognoses of headaches with epileptic EEG discharges were favorably good. In addition, we suggested that this type of headache belongs to simple partial seizures with autonomic symptoms or signs (ILAE 1981) rather than migraine variants.

\section{P-20}

\section{THE MIGRAINE CNS BASIC DEFECT: ITS NON INVASIVE} MEASUREMENT IN CHILDREN

M. Nicolodi, A. Torrini

Interuniversity Headache Centre, Foundation for Prevention and Therapy of Primary Pain and Headache, Florence, Italy; e-mail: m.nicolodi@email.it

The study is aimed to test a non invasive, semi objective tool for evaluating vascular hyperalgesia that is a sign of the CNS hyperexcitabili- 
ty characterizing migraine. The measurement of vascular hyperalgesia is independent of verbal ability. Hyperalgesia evidenced by overdistension of the veins of the upper limb was observed in 110 children (mean age, 8+5.6 SD) with migraine (IHS criteria), in 110 children (mean age, 8.2+4.4 SD) with anxiety and 110 children (8.5+4.6 SD) with depression (Wang and Zung Test, cut off 40). The 3 groups were matched for sex and social-cultural level. The manoeuvre consists in 1 min ischemia ( $95 \mathrm{~mm} \mathrm{Hg}$ ) followed by $1 \mathrm{~min}$ stasis $(55 \mathrm{~mm} \mathrm{Hg})$ during which the patient scored possible pain by a verbal analogue scale $0-4$. Pain scoring over 2 was reported by 7 children with anxiety, 1 child with depression and by all the children with migraine. Odds ratios indicate the association between vascular hyperalgesia and migraine. Samples of patients with anxiety and depression were undertaken to assess reliability and validity of the manoeuvre. Test-retest reliability $(r=0.92)$ was high. The instrument is sufficiently sensitive to be successful in permitting discrimination among illness groups. Construct validity was demonstrated against IHS criteria. The outcome agrees with the hypotheses about migraine mechanism. The manoeuvre is relevant in indicating the degree of CNS hyperexcitability and aids in discriminating the impact of psychological components.

\section{P-21 STRENGTH AND MOBILITY OF THE NECK-SHOULDER REGION IN ADOLESCENT HEADACHE}

${ }^{1}$ A. Oksanen, ${ }^{1}$ S. Viander, ${ }^{2}$ L. Metsähonkala,${ }^{3}$ M. Aromaa, ${ }^{4}$ P. Anttila, ${ }^{1}$ E. Jäppilä, ${ }^{1} J$. Salminen, ${ }^{5} \mathrm{H}$. Helenius, ${ }^{2,3}$ M. Sillanpää

${ }^{1}$ Departments of Physical Medicine and Rehabilitation, and ${ }^{2}$ Child Neurology, Turku University Central Hospital, University of Turku; ${ }^{3}$ Departments of Public Health, and ${ }^{5}$ Biostatistics, University of Turku; ${ }^{4}$ Child and Adolescent Health Care, Turku City Hospital, Turku, Finland; e-mail: airi.oksanen@tyks.fi

Although the association between muscular disorders of neck-shoulder region and tension-type headache and between decreased cervical mobility and headache has been reported in adults, only few data have been available conserning adolescent headache. The purpose of the present study was to examine the strength and mobility of the neckshoulder region in different headache types in adolescents. The strength and mobility of the neck-shoulder region were studied in 13year-old adolescents with or without headache. After a questionnaire study, 140 children with migraine or tension-type headache and 70 without headache were randomly selected for a face-to-face interview and clinical examination. After final classification of headache, the dynamic strength of the upper extremities, the mobility of both shoulders and the cervical mobility were measured in 59 children with migraine, 65 with tension-type headache and 59 headache-free controls. The girls with tension-type headache had lower upper extremity strength of both dominant and non-dominant sides and lower cervical rotation of dominant side compared to girls in the other study groups. The girls with migraine had lower upper extremity strength of nondominant side compared to girls in the control group. In boys no significant differences were found. Tension-type headache in girls is associated with signs of dysfunction of the neck-shoulder region. This finding might also have indications for treatment of headache.

\section{P-22 HEADACHES AS THE MANIFESTATION OF GENERALIZED EPILEPSIES}

A. Ölmez, G. Turanli, Ö. Soyer, M. Topçu

Hacettepe University, Faculty of Medicine, Department of Child

Neurology, Ankara, Turkey; e-mail: mtopcu@hacettepe.edu.tr

Headaches are common in childhood and adolescence. Generally EEG is reported not to be useful in the routine evaluation of the patients with recurrent headaches $(1,2)$. We report here three cases with paroxysmal headaches associated with generalized epileptiform activities. Patients were selected from the outpatient clinics of Pediatric Neurology Department of Hacettepe University, referred and evaluated because of recurrent headaches. Two of the patients were boys and the other was a 13.5 year old girl having headache for two years. She and one of the 5.5 year old boy had headaches in the morning with nausea. He felt vertigo once and the girl saw yellow colors in the evening for one time without headaches. The 10.5 year old boy had headache only 4 times in the last month and he didn't have any complaint other than headache lasting for an hour. EEG recordings of all the patients revealed generalized epileptiform activities. The epileptiform activites of the boys were activated during sleep. They had normal MRI. The girl was followed up for neurofibromatosis type 1 and her MRI had white matter hyperintensities associated with NF. All the patients were free of headaches after anti-epileptic treatment. A study from our hospital reported that $6.5 \%$ of patients with recurrent headaches had epileptic headaches and half of them had generalized epileptiform activity. Since association of the headaches with generalized spikes is limited in literature, we wanted to report our patients.

\section{P-23}

\section{CLINICAL CHARACTERISTICS OF PATIENTS WITH} HEADACHES AND EPILEPTIC DISCHARGES

A. Ölmez, G. Turanli, D. Yalnizoglu, M. Topçu

Hacettepe University, Faculty of Medicine, Department of Child Neurology, Ankara, Turkey; e-mail: mtopcu@hacettepe.edu.tr

Primary headaches and primary epilepsies share some interrelationships with each other (1). They may occur in the same person and one can trigger the other. They are also features of some epileptic syndromes like benign partial epilepsies of childhood and benign occipital epilepsy of childhood with occipital paroxysms (BOEP) (2). Patients were selected from the outpatient clinics of Child Neurology Department of Hacettepe University admitted with headache and seizure complaints. 6 of the patients were males and 4 were females. They were between 6-13 years of age. They had headaches as the only complaint or associated with the other complaints like nausea, vomiting, vertigo, visual symptoms and loss of concsciousness. Visual symptoms include, macropsia, micropsia, colored objects or lines and loss of vision. Two of the patients had only headache. Four of them had nausea and vomiting, two of them had vertigo. Different kinds of visual symptoms were found in five of the patients history. They all had epileptic activitis in their EEG recordings. Six of the patients had occipital foci and 3 of them were BOEP. Epileptic discharges were activated during sleep. Only two of them had abnormal MRI. They were all given antiepileptic treatment and one of the patients with only headache complaint was resistant to different drugs. Headache can be seen as the only or associated symptom of the partial epilepsies. We wanted to report the clinical and EEG characteristics of some of our patients.

\section{P-24}

TRANSCRANIAL MAGNETIC STIMULATION AND ABSOLUTE SILENT PERIOD IN ADOLESCENTS WITH MIGRAINE AND IDIOPATHIC GENERALIZED EPILEPSY

V. Tomov, E. Stoimenova, L. Belopitova

Clinic of Child Neurology, University Hospital of Neurology and Psychiatry, Sofia, Bulgaria; e-mail: bozholan@iph.bas.bg

Background The absolute silent period (ASP), known to be a reliable estimate of cortical inhibition capacity, was tested by performing Transcranial Magnetic Stimulation (TMS) in patients and controls. Methods 16 adolescents with migraine ( 8 girls and 8 boys) aged 10-16 years, 14 adolescents with idiopathic generalized epilepsy (5 girls and 9 boys) aged 10-15 years and 14 healthy controls (12 girls, 2 boys), aged 10-17 years were tested. ASP and its threshold were studied by measu- 
ring three consecutive stimulations of the right and left hemispheres. Mm. abductor policis breves were used for recording EMG and analyzing the ASP duration. Student's T-test for independent groups was performed. Results ASP threshold was found in the range of $64.6 \%-70.7 \%$ of maximum stimulating capacity in the control and epilepsy groups, with no statistical differences among them, while it was increased up to $76 \%-77 \%$ for the migraine patients. This increase in migraine patients in comparison to contorls was significant ( $p=0.03$ for both hemispheres). ASP duration was measured between 25 and $27 \mathrm{~ms}$ when stimulating the left heemisphere and between 24 and $34 \mathrm{~ms}$ when stimulating the right hemispehere, without statistical differences anong the three groups studied.

Conclusions The increased threshold of cortical inhibition in migraine patients is proof for dysfunction of brain inhibitory system. It is in good agreement with their specific clinical signs and behavioral problems.

\section{SECONDARY HEADACHES}

\section{P-25 \\ PACHYMENINGITIS: POSSIBLE PATHOGENIC BASIS OF CHRONIC HEADACHES IN CHILDREN \\ I. Almazov}

Meuhedet Health Care, Tel Aviv, Israel; e-mail: almazov@netvision.net.il

Background In the numerous reports on chronic headaches in children, neurological examination was the modality used, while meningeal symptoms were ignored. This is the first study to investigate a method that focuses on the presence of meningeal symptoms in children with chronic headaches.

Patients and methods The patient population comprised 1.437 patients aged 5-17 years who were examined by a pediatric neurologist in a routine outpatient practice over a 5-year period. Particular attention was paid to meningeal symptoms, including nuchal rigidity, Kernig's sign, Brudzinski's three signs (upper, middle and lower), the "tripod" and Guillain's signs.

Results Altogether, 833 (58\%) children suffered from migraine, of whom $12 \%$ were found to have some meningeal signs. Of the $604(42 \%)$ children with tension headaches, $97 \%$ had signs of the meningismus syndrome. Meningismus was manifested by all mentioned symptoms. This group of children (97\%), when bending the head forward had nuchal rigidity or complained of pain in the head, neck and epigastrium. Rest in a recumbent position usually brought relief from the headache.

Conclusions We contend that the anatomic basis of the tension headaches is meninges, particularly the dura mater. The dura mater has a pain-sensitive structure and is therefore susceptible to non-specific chronic pachymeningitis. Pachymeningitis is most likely the result of insignificant trauma of the head and/or back, or from infection by different agents.

\section{P-26 HEADACHE AND EPENDYMAL CYST: A CASE REPORT}

${ }^{1,2}$ O. Ferrari-Ginevra, ${ }^{3} \mathrm{C}$. Termine, ${ }^{1} \mathrm{M}$. Rossi, ${ }^{1} \mathrm{G}$. Lanzi ${ }^{1}$ Department of Child Neurology and Psychiatry, C. Mondino Institute, University of Pavia, Italy; ${ }^{2}$ Don Gnocchi Foundation, Centro S. Maria al Castello, Pessano, Italy; ${ }^{3}$ Child Neuropsychiatry Unit, University of Insubria Varese, Italy; e-mail: oreferrarig@libero.it

Headache is a common problem faced by the paediatrician or the child neuropsychiatrist. It can be difficult to distinguish the different types of headache in young children. This case report will review a case of a 12 years and 7 months old boy who experienced several episodes of intense headache with nausea, vomiting and blurred vision when awekining. He had his 1st headache attack 8 months before our observation; the pain was located at vertix and stopped few hours after assumption of NAIDs. Neurological examination revealed: head pain both on neck extension and lateralization, strabismus due to left lateral rectus palsy, bilateral mydriasis, continuous nistagmus in all gaze directions and dyplopia. Moreover there was a mild left arm weakness, asymmetrical increasing of reflex at legs (left>right) and ataxia. A brain CT scan revealed a mass located in the fourth ventricle and a MRI (by contrast injection) showed a cystic dilatation just in the fourth ventricle $(3.5 \times 3$ $\mathrm{cm}$ ), putting ahead the pons and the midbrain. The surgical excision of the ependymal cyst reduced symptoms. Six months later a MRI control showed a complete restitutio ad integrum. The boy has not yet headache and he attends his normal life activities.

\section{P-27}

\section{SINUSITIS IN CHRONIC OR RECURRENT HEADACHES: WHAT IS THE FREOUENCY OF DIAGNOSIS? DOES THE TREATMENT RESOLVE HEADACHES?}

N. Senbil, Y.K. Gürer

Dr. Sami Ulus Children's Hospital, Ankara, Turkey; e-mail: senbilon@ttnet.net.tr

Objective To determine the frequency of sinusitis diagnosis in children and adolescents with recurrent or chronic headaches and to invesNesrin Setigate the improvement of headache after sinusitis treatment.

Methods We examined 214 patients (115 girls, 99 boys, aged 4-16 years) referred for recurrent or chronic headaches. We asked all subjects whether sinusitis had been diagnosed previously and if so, we asked whether the headache was different and whether additional complaints such as fever, coughing, nasal discharge, postnasal discharge, and swelling in the eyes were present at the time of the sinusitis diagnosis. Finally, we asked whether a treatment of the sinusitis had an effect on the headache.

Results A diagnosis of sinusitis was reported by 116 patients (54.2\%). At the time of the sinusitis diagnosis $25 \%$ had at least one additional symptom, but $75 \%$ had none of those. Sinusitis treatment had no effect on the headache in $60.3 \%$, and a short-term effect in $8.6 \%$ and to a long-term effect in $31.1 \%$ of the patients. The rate of improvement was significantly larger in subjects with additional symptoms $(62 \%)$ than in those without $(32 \%)$.

Conclusions Sinusitis is frequently diagnosed in children and adolescents with recurrent or chronic headache, and a sinusitis treatment in these patients has frequently no effect on the headache. The data suggest that recurrent or chronic headaches in children and adolescents are frequently misdiagnosed and mistreated as sinusitis.

\section{P-28}

TOLOSA HUNT SYNDROME: A CASE REPORT

E. Tozzi, R. Savini, N. Fiorentini, E. Cicconi, R. De Colli

Clinic of Paediatrics, University of L'Aquila, Italy; e-mail: etozzi@univaq.it

A girl, 15 years old, presented at our observation because suffering from frontal and orbital headache, stabbing type,severe with abrupt onset and progressive evolution, perduring from 24 hours with pain in the eye left and palpebral ptosis. The girl appeared very suffering and very ansious. Clinical observation and neurological examination were normal, with the exception of ptosis. The pupils were normal in the reaction.In the anamnesis: a cold one week before. Mother and brother are suffering from migraine without aura. The girl at age of 10 months was hospitalized because of hypotonia and dizziness perduring for 48 hours. Diagnosis not certainly. At age of 10 years headache as migraine without aura treated with flunarizine and with partial remission. Same ophtalmoplegia was three months before and they improved spontaneously. For these reason she hospitalized in other town, were MR brain was performed and was normal. At first our examination MR brain and orbit was performed with and without contrast enhancement. This study revealed an image hyperintense in the lateral left muscle, augmented in size. The cavernous sinus and parasellar structures were normal. Steroid treatment relieve the 
pain in the patient and ophtalmoplegia disappeared after 72 hours. Follow-up of six months is normal. According recent data diagnosis in this patient is Tolosa Hunt syndrome with intraorbital inflammation. We present the case because of particular imaging.

\section{P-29 OPTIC NEURITIS IN CHILDREN: A RARE CAUSE OF HEADACHE \\ Y. Yilmaz, U. Isik, M. Berber \\ Marmara University, School of Medicine, Division of Child Neurology, Istanbul,Turkey; e-mail: erkyilmaz@e-kolay.net \\ Optic neuritis, predominantly a disease of young adults, is very rare in young children, in whom it is usually post- or para-infectious. Clinical manifestations of optic neuritis include loss of vision, headache, eye pain, dyschromatopsia, obscuration of vision in bright light. However, young children migth not explain their ophtalmological complaints and headache associated with loss of vision may be the main symptom. We report here clinical findings of three patients ( 3 boys between $6-8$ years of age) with optic neuritis and aim to emphasize that optic neuritis should be conside- red in the differantial diagnosis of acute headache even in young children.}

\section{P-29A \\ SECONDARY HEADACHE AS A SYMPTOM OF MOYA. MOYA DISEASE: A CASE REPORT}

V. Djuranovic, V. Mejaski Bosnjak, B. Marusic della Marina, L. Lujic Childrens Hospital Zagreb, Croatia; e-mail: IPerkovi@JNJCR.JNJ.com

We report an 18 years old boy, who was admitted in our Hospital at the age of ten, because of pulsating headaches (specially during physical training). He had no neurological dysabillities. His EEG and first brain CT scan were normal as well as fundoscopic examination, lumbar puncture and laboratory tests. Transcranial Color Duplex Doppler ultrasonography showed very high velocities in both ACA and right MCA, as a sign of suspected stenosis or spasm. The digital subtraction cerebral angiography was performed after few months of repeated headaches and unchanged Doppler US findings. It showed an image of high degree stenosis of A1 segment of both ACA and right MCA with signs of "steal sy" through posterior cerebral circulation. Brain MRI (performed one year later, at the age of thirtheen, after episodes of TIAs) showed ischemic infarction on the right temporooccipital region. During next four years, boy had repeated headaches, several episodes of TIAs and twice an ischaemic infarction, which was confirmed by CT. Brain MRI/MRA (performed at the age of seventheen) showed new cortical ischaemic infarction at the region of left paracentral gyrus. We suppose that the etiology of stenosis is vasculopathy: Moya-Moya disease. Other vasculopathies are excluded by laboratory tests and clinical elaboration. Today, at the age of eighteen, patient has antiagregation therapy by salicylate acid and topiramat as neuroprotektor. He has seldom headaches with parestesias of the extremities, but is clinically stable, with normal neurological, fundoscopic and EEG examinations.

\section{CLINICAL ASPECTS OF PRIMARY HEADACHES}

\section{P-30}

\section{CLINICAL CHARACTERISTICS OF MIGRAINE WITH AURA} IN CHILDHOOD

\section{Bojinova, L. Belopitova}

Clinic of Child Neurology, University Hospital of Neurology and

Psychiatry "St. Naum”, Sofia, Bulgaria; e-mail: tchamov@bulinfo.net

Background To analyze the peculiarities of the different forms of migraine with aura in children.
Patients 76 children aged from 2 to 16 years with migraine with aura. Results According to the symptoms of aura the diagnosed forms of migraine were: migraine with typical aura $(n=48$ or $63.1 \%, 2$ of which acephalgic attacks); migraine with prolonged aura ( $\mathrm{n}=3$ or $4 \%)$; familial hemiplegic migraine $(n=5$ or $6.5 \%)$, basilar migraine $(n=12$ or $15.9 \%)$; ophthalmoplegic migraine $(\mathrm{n}=3$ or $4 \%)$, alternant hemiplegia $(\mathrm{n}=1$ or $1,3 \%)$.The average age at the onset of the migraine was 8.8 years and of the appearance of aura- 10.9 years. The aura preceded the headache in $86.8 \%$. The aura symptoms were visual (photopsias $44.7 \%$, hemianopsias $30.3 \%$, ambliopia-unilateral in $5.2 \%$ or bilateral in $7.9 \%$ ), hemiparesthesia $(34.2 \%)$, vertigo $(14.5 \%)$, hemiparesis $(13.1 \%)$, ataxia (6.6\%), dysarthria and bilateral paresthesia $(5.3 \%)$. With somnolence were 10 children, predominantly with basilar migraine $(4 / 12$ or $33 \%)$, only one child had confusional state migraine. In children with typical aura $(\mathrm{n}=60)$ the frequently symptoms of aura were photopsia $(57 \%)$, hemianopsia $(38 \%)$, hemiparesthesia $(43 \%)$, hemiparesis $(16.7 \%)$, while for the basilar migraine - verigo and vomiting $(100 \%)$, nystagmus $(50 \%)$, ataxia $(42 \%)$, photopsias $(66.7 \%)$, bilateral ambliopia $(41 \%)$, bilateral paresthesias $(33 \%)$.

Conclusions Migraine without aura preceded years the typical aura symptoms, but this is uncommon for basilar migraine.

\section{P-31}

DIAGNOSES OF PRIMARY HEADACHES IN CHILDREN REVIEWED AT THE CHILDREN'S MEDICAL INSTITUTE, SINGAPORE

${ }^{I}$ S.C. Chong, ${ }^{2}$ K.J.L. Lim, ${ }^{1}$ H.T. Ong

${ }^{I}$ Children's Medical Institute, National University Hospital; ${ }^{2}$ Department of Paediatrics, National University of Singapore; e-mail: paev3@nus.edu.sg

Aim This prospective study aimed to evaluate the diagnosis of children with primary headaches who were referred to the paediatric neurology clinic.

Methods Questionnaires were completed by the children with assistance from their parents. Their headaches were classified according to the International Headache Society (IHS) criteria established in 1988. For paediatric migraine, the proposed modified diagnostic criteria by the Paediatric Headache Committee of the Association for Study of Headache in 1997, was used.

Results There were 151 responders from January 1999 to November 2003. Using the modified paediatric IHS classification $28.5 \%$ had migraine without aura, and $15.9 \%$ had migraine with aura (IHS diagnostic codes 1.1 and 1.2 respectively). Episodic tension headaches (IHS 2.1) made up 15.9\%; chronic tension headaches (IHS 2.2) 9.3\%; and benign exertional headaches (IHS 4.5) 1.3\%. The remaining $29.1 \%$ were classified as "headaches of the tension-type or migrainous type but not fulfilling IHS criteria" (IHS 2.3 and IHS 1.7 respectively) and "headaches not classifiable" (IHS 13.0)

Conclusions Majority of patients have either migraine or tension-type headaches. We had a significantly lower proportion of children who had migraine without aura when compared to reports from Barcelona, using the same modified IHS criteria for paediatric migraine. Epidemiology studies would be useful to determine if Singapore children indeed have a lower incidence of migraine without aura.

\section{P-32 \\ EARLIEST MIGRAINE MANIFESTATIONS IN LIFE \\ M.V. Francis}

Headache and Migraine Research Centre Cherthala, India; e-mail: mvfrancis@rediffmail.com

Objectives To document earliest migraine manifestations in life.

Methods After diagnosing migraine and documenting common migraine triggers in 3000 children aged 5 to 14 years their parents were 
questioned about various components of migraine manifestations observed by them during the early years (birth to 5 years) when these children were exposed to same triggers.

Results Common migraine triggers were exposure to sunlight $82 \%$ (2.560), daytime bus traveling 38\% (1.140), tension anxiety situations $27 \%$ (810), strenuous physical exercises $21 \%$ (630), hunger in $10 \%$ (301) and lack of sleep in $8 \%$ (243). Earliest of all the manifestations was travel sickness right from first month of life. Dislike to travel by bus, sleeping on mothers lap immediately after boarding the bus, increasingly sleepy as travel distance increases, nausea and vomiting when bus negotiates curves and hilly areas, periorbital oedema and conjunctival congestion with mild to moderate headpains were the other travel related symptoms reported. Complaining of mild to moderate periorbital and generalized headache without associated autonomic symptoms, dislike to play out in the sun, transient vomiting in between and immediately after playing under the sun, eye pain alone or associated with redness eyes and dizzy spells were the other sun exposure.

\section{P-33}

\section{PERIORBITAL AND REFRACTIVE MIGRAINES IN CHIL-} DREN AND ADOLESCENTS

M.V. Francis

Headache and Migraine Research Centre, Cherthala, India; e-mail: mvfrancis@rediffmail.com

Objective To diagnose periorbital headaches presenting without associated inflammatory eye signs in children and adolescents.

Methods 1.600 children and adolescents aged 5 to 12 years were studied over a period of 8 years. Exclusive criteria- fever and systemic illnesses. Diagnosis was made from a two step approach.

Results Of the 1.600 studied, 1152 (72\%) were suffering from migraine origin periorbital pain. Tension anxiety were diagnosed only in 18 $(1.1 \%)$. The common triggers precipitating migraine origin pains were exposure to sunlight, traveling by bus, hunger, tension anxiety situations, lack of sleep and strenuous physical exercises. Eye strain was one of the triggers in 32 patients who had uncorrected refractive errors and associated binocular muscle dysfunction.

Conclusions This study proves that the commonest cause of periorbital headpain without associated inflammatory eye signs in children and adolescents, is migraine. Tension anxiety aches are not common but a significant trigger for migraine origin pain. Brief migraine episodes and earliest migraine manifestations can mimick tension anxiety aches. Documenting common migraine triggers can immensely help in differentiating the two. Uncorrected refractive errors and associated binocular muscle dysfunction can trigger migraine origin periorbital headaches.

\section{P.34.}

\section{CHILDHOOD PERIODIC SYNDROMES (IHS 1.5) SOME USEFUL MARKERS}

\section{M.V. Francis}

Headache and Migraine Research Centre, Cherthala, India; e-mail: mvfrancis@rediffmail.com

Objective To document childhood periodic syndromes (IHS 1.5) and to suggest some clinically useful markers for diagnosing CPS.

Methods Of the 7.220 children and adolescents aged 5 to 15 years and diagnosed as migraine origin headpain over a period of 9 years, 34 were found to be getting childhood periodic syndromes. They were followed up for a minimum period of 2 years.

Results Brief paroxysmal episodes of dizzy spells or vertigo were reported by 23 . No case was diagnosed as alternating hemiplegia of childhood (even with a detailed past history from parents). Other migraine free equivalents (suggestive of periodic syndromes) diagnosed were cyclical vomiting (6) and periodic fever (3). Two of them aged 14 years reported severe dysmenorhoea with vertigo and migrai- ne origin autonomic symptoms. The most significant finding in the history was that, they all were getting migraine origin headpain when exposed to common migraine triggers like exposure to sunlight, traveling during daytime, hunger, strenous physical exercises and sleep disturbances. 28 mothers and 4 fathers were suffering from migraine headaches and their triggers were almost identical. From the history it was concluded that most of the dizzy spells or vertigo attacks were precipitated by either a single trigger or a combination of common triggers. Three with cyclical vomiting and one with periodic fever also reported.

\section{P-35 RELATIONSHIP BETWEEN POSTPARTUM HEADACHE AND HISTORY OF HEADACHE IN ADOLESCENCE AND YOUTH}

${ }^{1}$ S. Taavoni, ${ }^{2}$ M. Kaveh

Pain Research Department of ACECR, Iran University of Medical Sciences, Tehran, Iran; e-mail: staavoni@iums.ac.ir

Prevalence estimates for headache has varied in many population. Pregnancy influences headache patterns. Onset of some type of migraine is before age 20 .

Aims Identifying: (1) prevalence of postpartum headache in adolescence and youth; (2) correlation between postpartum headaches and: (a) chronic headache, (b) positive family history of chronic headache. Methods We randomly selected 190 samples from postpartum wards of one of the Hospital of Iran University of Medical Sciences in Tehran. (28 samples in age $14-19,75$ in $20-24,56$ in $25-29,21$ in 30-44) (Autumn 2001) X2 used.

Results Highest age groups were 20-24 years (39.47\%), 25-29 (29.47\%), 14-19 (14.74\%). Prevalence of migraine was $27.89 \%$, tension headache was $27.37 \%$, and postpartum headache was $23.16 \%$ (6.84\% migraine, $10 \%$ non-migraine, and $6.32 \%$ non-chronic headache). There was correlation between postpartum headache and: positive history of non-migraine headache $(p=0.007)$, and positive history of chronic headache $(p=0.015)$.

Conclusions Studies showed the highest rate of migraine in 18-25 years $(22.7 \%)$, and $28.7 \%$ in $30-39(1996,1992)$. We found the highest group of postpartum headache, in 20-24 (34.09\%, 8.78\% of entire samples), in 25-29 (25\%) and in 17-19 (20.45\%), (no postpartum headache in 14-16). We only found correlation between migraine and positive family history of headache $(p=0.000)$. There wasn't correlation between postpartum headache and positive history of migraine.

\section{PSYCHOLOGICAL AND PSYCHIATRIC ASPECTS}

\section{P-36}

A NEW VERSION OF THE MIGRAINE DISABILITY ASSESSMENT QUESTIONNAIRE FOR CHILDREN AND ADOLESCENTS WITH HEADACHE

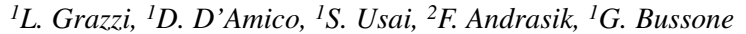

${ }^{I}$ National Neurological Institute "C. Besta”, Milan, Italy; ${ }^{2}$ Institute for Human and Machine Cognition, University of West Florida, Pensacola,FL,USA; e-mail: liciagrazzi@mac.com

Background The MIDAS (Migraine Disability Assessment) Questionnaire is the most extensively studied instrument to assess headache-related disability in adults. The purpose of this project was to develop a version of MIDAS specifically aimed to assess disability in young headache sufferers.

Patients and methods Two separate studies were conducted. A sample of 95 headache sufferers aged 7-17 completed an Italian version of the MIDAS Questionnaire for adults on 2 occasions for assessing testretest reliability. Participants were also questioned about the adequacy 
of the questionnaire. In the second study, 85 patients completed our modified Italian version of the MIDAS Questionnaire, based on information and suggestions obtained from the first study. The main changes concerned wording: the terms work, household, family, social, leisure were replaced with school, homework and physical activity. Testretest reliability was again assessed.

Results Our italian adaptation of the MIDAS showed high test-retest reliability for individual items and the overall score as well, with Spearman coefficients ranging from 0.69 to 0.82 .

Conclusions This adaptation of the MIDAS seems to be a more suitable instrument for testing disability in young headache sufferers. It can also be used to compare the functional impact of different headache forms and to record changes in disability after treatment.

\section{P-37 \\ PREVALENCE AND BURDEN OF HEADACHE IN CHILDREN AND ADOLESCENTS: UTILITY OF THE MIDAS \\ M. Heinrich, L. Morris, B. Kröner-Herwig \\ Department of Clinical Psychology and Psychotherapy, Göttingen, Germany; e-mail: mheinri@uni-goettingen.de}

The number of children with headache experience has increased during the past two decades. Estimated prevalence rates of pediatric headache vary between $3.5 \%$ and $56 \%$. Nearly $20 \%$ of children and adolescents experience headache once or more per week. Very few studies have focused on the functional disability of children suffering from headache. MIDAS, a questionnaire developed for the assessment of adults' functional disability due to headache, has recently been adapted for use with children. In the present study the MIDAS was administered via postal survey to a community-based sample of 100 families with a child between 7 and 14 years of age. Families with younger children (7 to 10) received one questionnaire to be filled out by a parent; families with older children (11 to 14 ) received two forms (child, adult) to complete. Questionnaires were returned by $82 \%$ of the sample. Headache experience was reported for $43 \%$ of the children in the past 6 months. One child fulfilled the IHS criteria for migraine, 19 children could be classified as having tension-type headache. The headaches caused school absence in 5 of the children. A further 24 children experienced functional disability according to parental response. The self-reported disability of the 11 to 14 year old children, however, indicates a parental tendency to underestimate the functional disability of their children. In summary, the MIDAS illustrated its value in the assessment of pediatric headache impact.

\section{P-38}

MIGRAINE AND TENSION-TYPE HEADACHE IN PATIENTS WITH EATING DISORDERS: RESULTS FROM A STUDY USING A SISTER-PAIR COMPARISON DESIGN

A. Karwautz, G. Wagner, A. Zormann, C. Wöber, Ç. Wöber-Bingöl

Headache Unit, Department of Neuropsychiatry of Childhood and Adolescents, Medical University of Vienna, Austria; e-mail: andreas.karwautz@univie.ac.at

Background To evaluate the relation between migraine, tension-type headache (TTH) and eating disorders (ED).

Methods We investigated 91 female patients who developed an ED (according to DSM-IV) between the age of 10 and 18 years. In order to be included in the study each patient had to have a non-eatingdisordered sister who served as control. Using this sister-pair comparison design provided optimal matching of age as well as of social and cultural variables and excluded gender differences. All subjects were asked whether they experienced headache earlier and if so a semi-structured interview was performed. Headache was diagnosed according to ICHD-II. Data presented are based on the onedigit level.
Results The prevalence of migraine and TTH did not differ in the 2 study groups. The lifetime prevalence of migraine was $26.4 \%$ in patients and $24.2 \%$ in controls and that of TTH was $37.4 \%$ and $26.4 \%$, respectively. Eight sister pairs each were concordant for the presence of migraine and TTH and 16 pairs were concordant for the absence of headache. In $50 \%$ of the patients headache occured before the ED.

Conclusions This clinic-based controlled study using a sister-pair comparison design shows no evidence of an increased prevalence of migraine and TTH among female patients with an ED.

\section{P-39 \\ AN EMPIRIC RESEARCH OF THE PRINCIPLE CAUSES OF THE "SYMPTOM HEADACHE" IN CHILDREN AND ADO- LESCENTS}

\section{P. Leone}

Department of Psychology, University of Rome, Italy; e-mail: pasqua.leone@uniromal.it

The remotion as Sigmund Freud's intuition was explored in children also by clinical research of Anna Freud and Melanie Klein. The remotion was considered one of the causes (the principle cause) of the "symptom headache", we have hypothesized that there is a risk factor very important because the augment of the symptom is very disagreeable. The symptom is not only the symptom but it is also what is before the symptom. The biopsychological approach and the psychodynamic approach to headache symptom are very important. The research (2001) and the observation of two parameters classified in the factors which originate the cefalgic crysis there are the emotion $36 \%$ and mental tired (33\%). The instruments that were used were the questionnaire of anxiety (by Busnelli and Dall'Aglio) and the C.D.S. (Scale of Depression, Tische, 1984).

Methods and results We proposed another research in which we observed a modality of psychological test consistent of the questionnaire invented by P.Leone on the psychic disease and of the test SPSSRPRS invented by P. Leone, 1999. Both tests were somministreded to 244 children (6-10 years old ) and to same number of adolescents (11-14 years old). The results are confirmed the biological and deterministic freudian hypothesis of remotion, because one of the principle causes of headache is the remotion as a mechanism of the Ego's defense and various aspects of remotion-repression.

\section{P-40}

TENSION-TYPE HEADACHES IN SCHOOLCHILDREN: PERSONALITY TRAITS AND BEHAVIOUR

Z. Mandic, D. Baraban, M. Boranic

Department of Pediatrics, University Hospital Osijek, Croatia; e-mail: dunja.baraban@hi.hinet.hr

Basic personality traits and specific behaviour characteristics were assess in 39 patients ( 30 girls; 12 to 15 years old) having chronic tension-type headache. Patients were referred for clinical examination to the Neural-Pediatrics Ward of the Department of Pediatrics, Osijek, Croatia. Eysenck Personality Questionnaire-Juniors, a new Croatian Personality Questionnaire of domination, aggression, introversion and ambition and Wechsler s Intelligence scale for Children (Revised), were applied for the testing. The scores obtained by patients in personality questionnaires were compared with averages scores normal sample of healthy pupil same ages. Our patients were found to have no signs of emotional instability. Their behaviour is prosocial, nonaggressive, and ambitious, aimed at the achievement of superior results at school and life although already quite successful in their studies. Tension arising from the school setting seem to be important factors triggering tension-type headaches in these children. 


\section{P-41 EVALUATION OF HEADACHE'S PEDIATRIC MANAGEMENT IN CHILDHOOD AND ADOLESCENCE}

${ }^{I}$ G.M. Marano, ${ }^{2}$ D. Lendvai, ${ }^{2}$ P. Verdecchia, ${ }^{2} R$. Crenca, ${ }^{2}$ S. Pittella, ${ }^{3}$ J. Osborn, ${ }^{4}$ P. Leone

${ }^{1}$ Department of Gynaec. Obstet. Pueric.; ${ }^{2}$ Department of Pediatrics, ${ }^{3}$ Department of Public Health Science; ${ }^{4}$ Department of Psych., University La Sapienza, Rome, Italy; e-mail: giovannamaria.marano@uniromal.it

Background Pediatricians skilled in Prevention Area could be helpful to evaluate such management by epidemiological methods. They could press for exchanging information about recent knowledge at different levels and individuate integrated strategies to consolidate the best practices assuring, with other Professional involved, well-being of Children with "Headache", in their surrounding growth and development. Patients and methods Clinical and psychological data collecting about 1.232 children sent to "Childhood and Adolescence Headaches' Center" c/o a Dept. of Pediatrics during the year 2002. Range of age: 3-14 years, both boys and girls.

Results (1) Clinical data allowed the ICH for 1.127 children, bringing out their risk factors. (2) Psychological data allowed to establish a frequency scale among factors causing headache. (3) Evaluation and provision of specific treatment and prophylaxis (5HTP), allowed to obtain a response in $80 \%$ this population.

Conclusions Prevention Pediatrics suggests to emphasize: (1) Strategical position of such a Center into a Dept. Area for integrate approach to Children's Headache; (2) leading role of skilled Pediatricians at the beginning of a diagnostic process; (3) by planning population-based studies to control risk and causal factors, such a Center could monitorize Children's Headaches as time goes on and contribute to prevention of Adults' Headache. We propose this model as irreplaceable Service to Childhood in the Prevention Planning with other services.

\section{P-42 \\ EATING DISORDERS IN CHILDREN AND ADOLESCENTS SUFFERING FROM MIGRAINE: THE NEED TO WATCH OVER}

M. Nicolodi, A. Torrini

Interuniversity Headache Centre, Foundation for Prevention and Therapy of Primary Pain and Headache, Florence, Italy; e-mail: m.nicolodi@email.it

We observed the eating attitudes of young migraine sufferers: Group 1 included 75 patients ( 35 males, 5.5 years+3.6 SD), Group 2 included 105 patients ( 43 males, $14.2+4.6 \mathrm{SD})$. Group $1 \mathrm{~A}(\mathrm{n}=100)$ and Group $2 \mathrm{~A}$ $(n=85)$ consisted in sex, age, social level matched groups of controls. The following instruments were used: TPQ for evaluation of novelty seeking, harm avoidance, reward dependence. Bulimia Investigatory Test, Eating Attitude Test for investigating oral control and dieting, Wang and Zung tests for mood disorders. Tests were adapted to meet children language. Tests were administered before and 1 year after antimigraine prophylaxis. Toronto Alexithymia Scale was administered to the parents of investigated subjects and evidenced no difference in the 4 groups. Coexistence characterized mood and eating disorders (Migraine: $37.7 \%$ bulimia, 55\% anorexia; Controls: $35.5 \%$ bulimia, $43.8 \%$ anorexia). Personality dimension in migraineours evidenced higher occurrence of harm avoidance $(21.3 \%$ vs $13 \%$ control children, $20.9 \%$ vs $6 \%$ control adolescents) and reward dependence (30.6\% vs $20 \%$ control children, $60 \%$ vs $29.4 \%$ control adolescents). In migraine sufferers bulimia is less frequent than anorexia (Anorexia: $6 \%$ vs $0.5 \%$ control children, $18 \%$ vs $0.8 \%$ control adolescents; Bulimia: $4 \%$ vs $2 \%$ control children, $10.4 \%$ vs $7 \%$ control adolescents). Both the eating disorders are more frequent in migraine than in controls $(p>0.01)$. The disorder diminished $(p>0.01)$ after antimigraine therapy.
P-43 ATTACHMENT DIMENSIONS AND HEADACHE INTENSITIES. AN ANALYSIS ON HEALTHY NURSERY; PRIMARY AND SECONDARY SCHOOL-CHILDREN

\section{G.G. Ostkirchen}

University Duisburg-Essen, Medical Department, Clinics of Neurology, Essen, Germany; e-mail: gabriele.ostkirchen@uni-essen.de

The internal working-model on attachment dimensions changes with significant emotional experiences. Aversive experiences (e.g. headaches) activate the attachment-system which is motivating the child to look for protection. Certainly tied children behave more competently in conflict-situations and show adequate emotional regulation. How do attachment dimensions correlate with headache intensities in healthy children? 139 children $<71 \mathrm{~m}, 68 \mathrm{f}$, age $5-15$ years $>$ answered the Trudewind attachment scale assessing 5 areas and 4 interactive styles. The bonding qualities are determined for each attachment dimension. Estimated headache intensities (VAS 0-10; self-experienced = VAS-se; imagined = VAS-im; difference $=$ VAS-im - VAS-se) are registered Partial correlations are performed by SPSS. Significant correlations between certain $(\mathrm{r}=0.413, p=0.000)$, uncertain avoiding $(\mathrm{r}=-0.588$, $p=0.000)$ and uncertain ambivalent bonding qualities. ( $\mathrm{r}=-0.675$, $p=0.000$ ) meet theoretical expectations. VAS-se (MW 4,789, SD 3,249) and VAS-im (MW 6,603, SD 2,321) are positively correlated $(\mathrm{r}=0.400, p=0.000)$. The discrepancy measure (MW 1,773, SD 3,130) is rectified with VAS-im $(\mathrm{r}=0.326 ; p=0.000)$ and opposite to VAS-se $(\mathrm{r}=-0.724, p=0.000)$. This sample predominantly shows low correlations between attachment dimensions and headache intensities. The rarely found significant correlations are ambiguous and not in the unison with theoretical considerations.

\section{TREATMENT}

\section{P-44}

PHARMACOLOGICAL VERSUS LIMITED CONTACT BEHAVIORAL TREATMENT FOR PEDIATRIC TENSION-TYPE HEADACHE: PRELIMINARY FINDINGS

${ }^{1}$ F. Andrasik, ${ }^{2}$ L. Grazzi, ${ }^{2}$ S. Usai, ${ }^{2}$ D. D'Amico, ${ }^{2}$ G. Bussone ${ }^{1}$ Institute for Human and Machine Cognition, University of West Florida, Pensacola, FL, USA; ${ }^{2}$ National Neurological Institute " $C$. Besta”, Milan, Italy; e-mail: fandrasik@ihmc.us

Background The purpose of this study was to compare relaxation training (in a limited contact format) and amitriptyline in the treatment of young Tension-Type Headache sufferers, as few direct comparisons of this type have been reported.

Patients and methods Thirty-three patients have begun the trial: 17 assigned to pharmacological treatment (10 females, 7 males; mean age $=13.1$ ) and 16 to behavioral treatment ( 12 females, 4 males; mean age =12.9). Headache $\log$ s and an Italian version of the MIDAS Questionnaire are serving as the outcome measures.

Results Days of headache activity decreased by $67 \%$ and $47 \%$ and MIDAS scores decreased by $78 \%$ and $55 \%$ for pharmacological and behavioral treatment, respectively, at 3 months. In the pharmacological group, however, only 10 patients came to the clinic for the follow-up visit. The remaining 7 refused to continue because of the onset of side effects and/or non-compliance. In the behavioral group, all patients have remained in the study thus far, with good attendance and regular home practice. These patients appear to be compliant and accepting of treatment although we did not assess this formally.

Conclusions Although the clinical results are similar in both groups, relaxation therapy seems to be more accepted than pharmacological therapy. These data, however, are preliminary and the sample sizes are small, so these conclusions are tentative. We will continue our data collection through 12 months. 


\section{P-45 \\ STUDIES OF THE THERAPEUTICAL EFFICACY OF DEPAKINE CHRONO AND FLUNARIZINE FOR PROPHYLAC- TIC TREAT}

V. Bojinova, L. Belopitova

Clinic of Child Neurology, University Hospital of Neurology and Psychiatry "St. Naum”, Sofia, Bulgaria; e-mail: tchamov@bulinfo.net

Background To evaluate the therapeutical effectiveness of Depakine Chrono and Flunarizine for prophylaxis of childhood migraine.

Patients and methods 60 children aged 8-16 years, 36 of which with migraine with aura and 24- with migraine without aura. Thirty children (24 with aura and 6 without aura, 14 of which with EEG abnormalities) were treated with Depakine Chrono - $15 \mathrm{mg} / \mathrm{kg} /$ daily for a period of 6 months. Other 30 children were treated with Flunarizine $5 \mathrm{mg} /$ daily for the same period. The monthly attacks' frequency was evaluated before the treatment and during the treatment. EEG was done before the treatment and on the 3rd and 6th month.

Results The clinical efficacy of Depakine Chrono and Flunarizine used for migraine prophylaxis was similar for the two patient groups. Until the 3rd month the number of children-responders increased - 28 children $(93.3 \%)$ out of Depakine Chrono group and 25 children (86.7\%) of Flunarizine group: in $73.3 \%$ of the cases, treated with Depakine Chrono and $66.7 \%$ of the children, treated with Flunarizine the migraine attacks disappeared; six children (20\%) of the two groups were with reduction of the frequency and of the severity over $50 \%$. This good efficacy was available until the end of the study. Depakine Chrono was applied on children who have migraine with aura $(\mathrm{n}=24)$ and/or EEG abnormalities $(\mathrm{n}=14)$.

Conclusions Depakine Chrono and Flunarizine are effective and useful for prophylaxis of migraine in childhood.

\section{P-46 \\ LONG-TERM USE OF SUMATRIPTAN NASAL SPRAY IS WELL-TOLERATED IN ADOLESCENT MIGRAINEURS}

${ }^{I}$ A. Dowson, ${ }^{2}$ L. Lisk, ${ }^{3}$ C. Webster, ${ }^{3}$ M. Richardson

${ }^{1}$ King's Headache Service, London, UK, ${ }^{2}$ GlaxoSmithKline, Greenford, UK; ${ }^{3}$ GlaxoSmithKline, North Carolina, USA; e-mail: DrAndyDowson@dowsona.fsnet.co.uk

Objective To review the long-term tolerability of sumatriptan nasal spray (SNS) $10 \mathrm{mg}$ and $20 \mathrm{mg}$ in adolescent migraineurs.

Background SNS is an effective and well tolerated treatment in adolescents. Two long-term tolerability studies are described.

Methods Migraineurs aged 12-17 years treated all migraine attacks for up to 12 months in two open-label studies (SUMA3006 \& SUM40276). Subjects started treatment with either $10 \mathrm{mg}$ or $20 \mathrm{mg}$ of SNS; titration of the dose was possible in both studies. Adverse events (AEs) were recorded, ECG and laboratory evaluations were performed.

Results 921 subjects treated 7.990 attacks with SNS. Too few attacks were treated with the $5 \mathrm{mg}$ dose $(\mathrm{N}=66)$ to reach meaningful conclusions. 1.978 attacks were treated with SNS $10 \mathrm{mg}$ and 5.944 attacks were treated with SNS $20 \mathrm{mg}$. At least one AE was reported in $39 \%$ and $31 \%$ of attacks for $10 \mathrm{mg}$ and $20 \mathrm{mg}$ respectively. Taste disturbance was reported in $29 \%$ of $10 \mathrm{mg}$ attacks and $19 \%$ of $20 \mathrm{mg}$ attacks. Only $5 \%$ of subjects withdrew from the studies due to AEs. Less than $1 \%$ of attacks were associated with serious AEs. No meaningful increase in AEs was found for $20 \mathrm{mg}$ compared to $10 \mathrm{mg}$ in those patients who used both doses during the studies. No subject experienced any drug-related changes in ECG, vital signs or nasal assessments. Laboratory parameters showed no meaningful patterns of abnormalities.

Conclusions Sumatriptan Nasal Spray is well tolerated during longterm use by adolescent migraineurs.

\section{P-47}

EFFICACY AND SAFETY OF TOPIRAMATE FOR MIGRAINE PREVENTION IN ADOLESCENTS

${ }^{1}$ A. Eikermann, ${ }^{2}$ P. Winner, ${ }^{1}$ J. Schmitt, ${ }^{1}$ W. Neto, ${ }^{3}$ D. Jacobs

${ }^{I}$ Klinik für Neurologie, Universitätsklinik Essen, Essen, DR; ${ }^{2}$ Palm Beach Headache Ctr, West Palm Beach, FL, USA; ${ }^{3}$ Johnson\&Johnson Pharmaceutical Research and Development, Raritan, New Jersey, USA; e-mail: astrid.eikermann@uni-essen.de

Background In 3 placebo-controlled studies including $>1500$ patients 12-65 years old, topiramate (TPM) $100 \mathrm{mg} /$ day was consistently found to be effective for migraine prevention. Objective: to evaluate efficacy and safety of TPM in the adolescent subset after pooling of data.

Patients and methods TPM was escalated with $25 \mathrm{mg} /$ day weekly over 8 weeks to target doses of 50,100 and $200 \mathrm{mg} /$ day (continued for 4 months). Change in mean monthly migraine frequency vs baseline (primary efficacy parameter), responder rate (at least $50 \%$ reduction in monthly migraine frequency), change in mean monthly migraine days, mean monthly days requiring rescue medication, and safety data were analysed in the subset of adolescents 12-18 years old.

Results Of 55 adolescents, 14 received placebo, 14 TPM-50, 13 TPM-100 and 14 TPM-200. Monthly migraine frequency (4.6-6.2 at baseline) decreased by 0.63 with TPM-50, 2.99 with TPM-100 and by 2.56 with TPM-200 vs 0.91 with placebo ( $p>0.05)$. TPM-100 significantly reduced the mean monthly days with acute medication use when compared to placebo $(-3.0$ vs $-1.4 ; p=0.042)$. Results approached significance with TPM-100 for the responder rate (62\% vs $21 \%$; $p=0.054)$ and for the change in mean monthly migraine days ( $-4.1 \mathrm{vs}$ $-0.7 ; p=0.056)$. Topiramate was generally well tolerated.

Conclusions Despite the small sample size, the results indicate that TPM is effective for migraine prevention in adolescents. Study of larger groups is warranted.

\section{P-48}

THE VALUE OF AN EDUCATIONAL PROGRAM FOR CHILDREN WITH DISABLING HEADACHES

K.U. Farmer, R.K. Cady

Headache Care Center, Springfield, Missouri, USA; e-mail: kfarmer@primarycarenet.org

Objective To assess the number of significant educational facts about migraine absorbed by children after watching a brief, narrated slide show program.

Methods Subjects: 10 migraine sufferers between the ages of 5 and 12, patients at a Midwest clinic, volunteered to participate in the study. Measure: Pre- and post-tests were administered that elicited the subjects' knowledge of their headache pattern, biofeedback, headache diary, triggers, aura, and where migraine begins. Procedure: In groups of 3 or 4 , children, accompanied by a parent, were administered the pre-questionnaire. The children watched a 7-minute slide show program, "Tango the Tiger Gets a Headache", which was followed by the post-test.

Results $50 \%$ of the children gained knowledge about aura and biofeedback. One-third said they would keep a diary; 17\% learned that certain foods can be triggers. In terms of treatment plans, $50 \%$ indicated that medicine stopped migraines; $33 \%$ believed sleep stopped migraine; and $17 \%$ considered resting as a way to stop migraine. $33 \%$ liked the lead character Tango the best; $67 \%$ disliked nothing about the slide program.

Conclusions Children who were already being treated for migraine gained significant knowledge by watching a slide show program which will help them better control their migraines. 
P-49

THE EFFECTIVENESS OF FLUNARIZINE IN THE PROPHY. LACTIC TREATMENT OF PEDIATRIC MIGRAINE SHOWED BY BRAIN SPECT

\section{M.A. Flores}

National Pain Management Training Center, Pediatric Pain Clinic, General Hospital of México; e-mail: promed@podernet.com.mx

Background Flunarizine has been shown to be effective in migraine prophylaxis in control trials in children, it is recommended by the German Headache Society. One of the clinical applications of the Single Photon Emission Computed Tomography (SPECT) is Migraine, it has been also used to show the effect of some medication's induced migraine and to examine the effect of antimigrain drugs during migraine headache.

Objective To show the effective use of Flunarizine in pediatric migraine, demonstrated by Brain SPECT.

Design We studied a group of 6 pediatric subjects: 2 males and 4 females, ages 3-14 years with migraine (IHS criteria), who have normal computed tomography and normal electroencephalogram. All the subjects were treated prophylacticly with Flunarizine $5 \mathrm{mg}$ per day and $2.5 \mathrm{mg}$ (in the 3 year old subject) during 3 months underwent single photon emission computer tomography (SPECT) using technetium Tc 99m ethyl cysteinate dimer before and after treatment.

Results The SPECT images revealed different areas of focal hypoperfusion in frontal, temporal, parietal and occipital areas before prophylactic treatment in all cases. In tree cases the perfusion improved in the same areas after the treatment and in the other three patients observed the perfusion became completely normal after the intervention.

Conclusions We conclude that Flunarizine is effective, demonstrated by SPECT, which is a useful tool to evaluate the effectiveness of antimigraine drugs.

\section{P-50}

TO ASSESS THE IMPACT OF TRIGGER AVOIDANCE AND APPLICATION OF TOPICAL DICLOFENAC IN MIGRAINE HEADACHES IN CHILDREN AND ADOLESCENTS

\section{M.V. Francis}

Headache and Migraine Research Centre, Cherthala, India; e-mail: mvfrancis@rediffmail.com

Objective To assess the impact of trigger avoidance and application of topical diclofenac in migraine headaches in children and adolescents.

Methods Retrospective study. 6000 children and adolescents were diagnosed as migraine during a period of 9 years and 3800 were followedup for a duration of 4 years. All triggers were recorded and common triggers were identified. Parents and teachers were advised regarding measures to avoid common triggers. Topical application of diclofenac was advised as a first line treatment in all.

Results The common triggers were exposure to sunlight $82 \%$ (4920), daytime bus travelling $42 \%$ (2520), strenuous physical exercises $23 \%$ (1380) and tension anxiety situations $21 \%$ (1260). Two or more triggers were reported by $41 \%$ (2460)of all patients studied. Diclofenac ointment (diclofenac diethylammonium equivalent to diclofenac $1 \%$ ) was prescribed in all as a first line treatment. 67\% of 3800 (2546) reported more than $50 \%$ improvement in the severity and frequency of their migraine headaches. Avoidance of common triggers (hat with a wide brim, wrap around sunglasses, umbrellas, avoiding sun exposure during school assembly sessions and physical training programmes, etc.).

Conclusions Avoiding common migraine triggers and topical application of diclofenac will have tremendous impact on the course of migraine headaches in children and adolescents.
P-51 MAGNESIUM AS A TREATMENT FOR PEDIATRIC TENSIONTYPE HEADACHE: A CLINICAL REPLICATION SERIES

${ }^{1}$ L. Grazzi, ${ }^{2}$ F. Andrasik, ${ }^{l}$ S. Usai, ${ }^{1}$ G. Bussone

${ }^{I}$ National Neurological Institute "C. Besta" Milan, Italy; ${ }^{2}$ Institute for Human and Machine Cognition, University of West Florida, Pensacola,FL,USA; e-mail: liciagrazzi@mac.com

Background Clinicians caring for young headache sufferers are hampered by the absence of safe, well-tolerated, and efficacious preventive agents. Investigations with adult and child migraineurs have demonstrated the usefulness of magnesium supplementation. Our purpose was to determine the initial utility of magnesium salt as a treatment for pediatric episodic and chronic tension-type headache (TTH).

Patients and methods Five children/adolescents with episodic and four children/adolescents with chronic TTH were treated with $2.25 \mathrm{~g}$ of magnesium pidolate twice per day for two months and then followed for one year, in a clinical replication series. Anxiety and depression were monitored as well.

Results The patients with episodic TTH revealed $78.4 \%$ symptom reduction, with $80 \%$ of the sample achieving reductions greater than $50 \%$. The patients with chronic TTH revealed $87.3 \%$ symptom reduction, with $100 \%$ of the sample achieving reductions greater than $50 \%$. Analgesic consumption decreased significantly for chronic TTH. Only one child consumed medication in the episodic TTH group. No significant changes occurred with respect to depression and anxiety, but these measures were not clinically elevated at the start of treatment. Conclusions Although this clinical replication series is uncontrolled, the initial findings are encouraging and suggest that controlled research is warranted.

\section{P-52}

TREATMENT OF MIGRAINE IN CHILDREN AND ADOLESCENTS: A REVIEW OF EFFICACY DATA WITH SUMATRIP. TAN NASAL SPRAY (SNS)

${ }^{1}$ M. Hämäläinen, ${ }^{2}$ C. Webster, ${ }^{3}$ L. Lisk, M. Jones

${ }^{1}$ Hospital for Children and Adolescents, University of Helsinki, Finland; ${ }^{2}$ GlaxoSmithKline, North Carolina, USA; ${ }^{3}$ GlaxoSmithKline, Greenford, UK, e-mail: Mirja.Hamalainen@hus.fi

Background Efficacy of oral triptans is difficult to demonstrate in young people with migraine. These prospective studies aimed to establish the efficacy of SNS in this population.

Methods Efficacy data from 7 studies in children and adolescents were evaluated.

Results 782 patients aged 12 to 17 years were enrolled in 2 controlled studies. SNS was significantly more effective than placebo. In SUM40019, headache relief (HR) at $2 \mathrm{~h}$ was achieved by $64 \%$ (SNS) versus $39 \%$ (placebo) $(p<0.05)$. In SUMA3005, HR at $1 \mathrm{~h}$ was reported by $47 \%-56 \%$ (SNS) versus $41 \%$ (placebo) $(p<0.05)$. Five small studies enrolled 172 patients aged under 12 years. SNS was significantly more effective than placebo in 2 controlled studies. Headache relief (HR) at 2 hours was achieved by $86 \%$ and $64 \%$ (SNS) versus $43 \%$ and $42 \%$ (placebo). HR at 2 hours was reported in $77 \%, 86 \%$ and $78 \%$ of patients in 3 uncontrolled studies. Taste disturbance was the most frequently reported adverse event. Conclusions Sumatriptan Nasal Spray allows the benefits of triptan therapy to be extended to children and adolescents. SNS is effective and well tolerated in the treatment of migraine attacks in those aged under 17 years.

\section{P-53} REABILITATION OF CHILDREN WITH CHRONIC TENSION

I.G. Izmaylova

Astrakhan State Medical Academy, Astrakhan, Russia; e-mail: astrbii@astranet.ru

With the aim of peculiarities studies of chronic tension type headache $(\mathrm{CTH})$ and working-out of complex pathogenetic therapy. We observed 
270 children of $12-17$ years with CTH, $57 \%$ of patients had a dysfunction of pericranial and cervical muscles. At first the headache was episodic connected with emotional and mental tension. $77 \%$ of children had complicated perinatal anamnesies, $100 \%$ - various psychogenesis connected with unfavourable situation in the family (86\%), pathologic relations between children and parents $(56 \%)$. All children had the diagnoses of psychovegetative syndrome. In complex system of rehabilitation of children with CTH there were used fluvoxamine (fevarin) 25-75 mg at night in combination with tanacan (Ginkgo Biloba) $80-120 \mathrm{mg}$ a day dyring 2 months; in muscular-tonic manifestation midocalm $25-75 \mathrm{mg}$ a day or sirdalude $2-6 \mathrm{mg}$ a day 2 weeks. We physiotherapy, rational ex-planatory psychotherapy, respiratory relaxative training, and phytotherapy. Dynamic study showed real decrease of asteno-vegetative and alarm-depressive disturbances close to normal data, decrease of intensity of CTH to 2,7 according to visual analogue scale in $30 \%$, complete disappearance of $\mathrm{CTH}$ in $70 \%$. The quality of life increased on $40 \%$. Effective therapy must include, except medicinal material, a wide range of physio-, reflexe-, phyto-, psycho-therapy. A great importance is given to psychotherapeutic correction of pathologic children-parents relations.

\section{P-54 \\ MINIMAL THERAPEUTIC INTERVENTION IN CHILDREN AND ADOLESCENTS WITH PRIMARY HEADACHE DEPEN- DENT ON PSYCHIATRIC COMORBIDITY}

U. Just, R. Oelkers-Ax, C. Schlotter, P. Parzer, F. Resch

Department of Child and Adolescent Psychiatry, University of Heidelberg, Germany; e-mail: ulrike.just@kikli.ma.uni-heidelberg.de

Objective Psychiatric comorbidity is an important risk factor for chronification of primary headache into adulthood. Multimodal psychological therapeutic program aims on prevention of chronification, but they are very expensive, time-intensive and need many personal resources. Previous investigation showed clinically relevant psychiatric problems in about $30 \%$ of 128 children with primary headache. The aim of this study is to investigate the success of a resource saving single minimal psycho-educative intervention dependent on psychiatric comorbidity.

Methods The influence of two counselling sessions was investigated in a prospective parallel group design in children with primary headache (according IHS, codes $1.1,1.2,2.1) 30$ with and 30 without clinical relevant psychiatric problems (measured by DIPS, CBCL, AFS, DIKJ) aged between 6 and 12 years. Clinical relevance of behavioural and emotional problems was defined according to Achenbach as CBCL - Total Problem Score T ? 64. In children without clinically relevant psychiatric problems but not in children with clinically relevant problems a significant reduction of headache attacks is expected. The frequency of headache attacks over time we calculated with a poissonregression for repeated measurements, therapeutic effects are investigated in a unifactorial ANOVA-design.

Results Preliminary results show a significant reduction of frequency of headache attacks over time in both groups.

\section{P-55 \\ EXAMINATION TO THE EFFECT OF 5HT1B/1D RECEPTOR OPERATION MEDICINE OVER CYCLIC VOMITING SYN- DROME IN JAPAN}

S. Kaneko, T. Hikita, N. Nakamoto, Y. Fujii, H. Kodama, Y. Yanagawa Department of Pediatrics, Teikyo University, School of Medicine, Japan; e-mail: sono-kaneko@tcn-catv.ne.jp

Conception of cyclic vomiting (abbreviated with CVS) was proposed in 1882 by Gee. The clinical feature is automatic neuropathy-shaped sudden intense vomiting, headache and endocrinological aberration to repeat itself. We often experience a patient presenting such a symptom in a medical care of pediatrics. In late years automatic neuropathy pays attention in Europe and America and it is positioned as a disease of nonepileptic paroxymal disorders and one of migraine variant because of an efficacy of tranquilizing agent. However, "autointoxication", "acetonemic vomiting", "periodicity ACTH-ADH ejection symptomcomplex" is called in various name in our country, and there are various hypotheses such as autonomic nerve aberration, aberration of endocrinology, digestive system aberration, metabolic disorder, and it is controversial. We report three cases with CVS treated by 5HT 1 $\mathrm{B} / 1 \mathrm{D}$ receptor agonist from a point of view as migraine variant and got higher efficacy in two of them. The concept of CVS in our country is not unified, so that the validity of $5 \mathrm{HT} 1 \mathrm{~B} / 1 \mathrm{D}$ receptor agonist to CVS is a future examination subject.

\section{P-56 \\ PHARMACOKINETICS OF ZOLMITRIPTAN NASAL SPRAY IN ADULT AND ADOLESCENT MIGRAINEURS BETWEEN MIGRAINE ATTACKS}

${ }^{1}$ S. Linder, ${ }^{2} P$. Winner, ${ }^{3} W$. Wasiewski, ${ }^{3}$ S. Ryan, ${ }^{4} M$. Kågedal

${ }^{1}$ Dallas Pediatric Neurology Assoc., Dallas, USA; ${ }^{2}$ Palm Beach

Headache Center, Florida, USA; ${ }^{3}$ AstraZeneca, Wilmington, USA;

${ }^{4}$ AstraZeneca, Södertälje, Sweden; e-mail: DPNASusanne@aol.com

Background This study compared the pharmacokinetics (PK) and tolerability of zolmitriptan nasal spray in adolescent and adult migraineurs between migraine attacks.

Patients and methods 15 adolescent and 15 adult migraineurs received a single dose of zolmitriptan $5 \mathrm{mg}$ nasal spray. Samples were collected at $0.25,0.5,1,2,4,6,8$, and $10 \mathrm{~h}$ for PK analysis of zolmitriptan and active metabolite $183 \mathrm{C} 91$.

Results Plasma concentration-time curves for zolmitriptan and 183C91 were similar in adolescents and adults. The geometric mean $(90 \% \mathrm{CI})$ of the ratios (adolescent/adult) were: AUC(0-8) 0.87 (0.61-1.25) and Cmax 0.97 (0.70-1.34) for zolmitriptan; AUC (0-8) 1.27 (0.94-1.70) and Cmax 1.17 (0.79-1.72) for 183C91. Median tmax in both populations was $2.0 \mathrm{~h}$ for zolmitriptan and $4.0 \mathrm{~h}$ for $183 \mathrm{C} 91$; mean $\mathrm{t}$ ? was $3.0 \mathrm{~h}$ in adolescents vs $3.8 \mathrm{~h}$ in adults for zolmitriptan and $3.4 \mathrm{~h}$ vs $8.0 \mathrm{~h}$ for $183 \mathrm{C} 91$. Zolmitriptan was well tolerated: similar adverse event (AE) frequencies in adolescents and adults; no serious AEs or changes of concern in vital signs or laboratory tests.

Conclusions Zolmitriptan and 183C91 PK profiles were similar in adolescent and adult migraineurs after a $5 \mathrm{mg}$ dose of zolmitriptan nasal spray. Given the very fast onset of action seen in clinical trials in adults, zolmitriptan nasal spray could be a good treatment for adolescent migraine. Zolmitriptan nasal spray was well tolerated in adolescent and adult migraineurs.

\section{P-57 \\ A COGNITIVE-BEHAVIOURAL PROGRAM FOR ADOLES- CENTS WITH CHRONIC PAIN: HEADACHE COMPARED WITH PAIN AT OTHER LOCATIONS}

${ }^{1,2}$ V. Merlijn, ${ }^{1} \mathrm{~J}$. Hunfeld, ${ }^{2} \mathrm{H}$. van der Wouden, ${ }^{2} \mathrm{~B}$. Koes, ${ }^{1} \mathrm{~J}$. Passchier ${ }^{I}$ Department of Medical Psychology and Psychotherapy, ${ }^{2}$ Department of General Practice, Erasmus Medical Center Rotterdam, The Netherlands; e-mail: v.merlijn@erasmusmc.nl

The prevalence of chronic pain increases in adolescence. Common complaints are headache, back pain and limb pain, often resulting in considerable functional disability. Furthermore, chronic pain has substantial impact on the life of the adolescents and their families. A number of psychosocial factors have been associated with the onset, exacerbation and/or maintenance of chronic pain in adolescents. Based on former findings of our research group, we have developed a model on the quality of life of adolescents with chronic pain in which psychosocial factors (vulnerability, reinforcement, modelling and coping) are 
taken into account. This model was used as a guide in developing a cognitive-behavioural program for adolescents with chronic pain at different locations. The program consists of five group meetings alternated with self-management weeks (plus telephone contacts). The social context of the adolescents is addressed by involving parents and peers in the program. The program, its feasibility and its efficacy, evaluated in a randomized controlled trial (experimental group $n=20$ and control group $n=18$ ), will be presented for adolescents with headache and those with pain at other locations.

\section{P-58 \\ MIGRAINE PROPHYLAXIS FOR CHILDREN BY THE PHY TOPHARMACEUTICAL BUTTERBUR ROOT EXTRACT PETA- DOLEX \\ R. Pothmann}

Pediatric Pain Center, Hamburg, Germany; e-mail: pothmann@aol.com

Due to results of 2 controlled clinical studies on adults, which showed that the phytopharmaceutical butterbur root extract Petadolex is effective and well-tolerated, an open, prospective study was carried out in a multi-centric design on 108 children 6 to 17 years old. The study participants suffered from migraines for more than one year, at least 3 attacks per quarter year. A treatment phase was followed by a medication-free observation period, each 4 month. School children younger than 9 received $2 \times 25 \mathrm{mg}$ ( $2 \times 1$ capsule), while children 10 years and older received $2 \times 50 \mathrm{mg}$ ( $2 \times 2$ capsules). Headaches were recorded in migraine journals especially designed for children. 88 percent of the 6-9 years old children and 74\% of the 10-17 years old ones reported less attacks. This positive effect remained during follow-up. Duration of the attacks was reduced from 9.6-10.2 to 6.4-7.3 hours. The medication was well-tolerated by $85 \%$ of the $6-9$ years old and $89 \%$ of the $10-17$ years old. There were 8 documented undesired effects, including 3 cases of "belching" with possible correlation with the drug intake. Effectiveness and low rate of side-effects in the pediatric migraine study are comparable to the results of the 2001 International PlaceboControlled Petadolex Study for Adults. In general butterbur root extract seems to be an effective, well-tolerated first-choice prophylactic migraine prophylaxis option for children and teenagers.

\section{P-59}

HEADACHE SUPPORT FOR CHILDREN, FAMILIES AND SCHOOLS

K. Shannon

World Headache Alliance, Canada; e-mail: KaryShannon@sympatico.ca

Objectives To review support materials available for children, their families and school for commonality and best practices.

Background World Headache Alliance (WHA) works with non-medical headache organizations in 26 countries. Many provide services to families who struggle with the burden of headache. Because of ethical, practical and financial concerns, less research is focussed on children than adults in epidemiology and treatment options. Families often feel they have nowhere to turn for support and information.

Methods WHA polled 42 member organizations to request materials and information for review. Materials were assessed on markers of best practices of plain language and health literacy. Support programmes were ranked by audience and method.

Results $23.8 \%$ of organizations responded. Materials that were common across cultural, regional and language groups included calendars/diaries, educational materials for teachers and information on nonpharmaceutical treatment options. Of those that responded, 50\% provided interactive opportunities with art, drawing, poetry and writing competitions. Public meetings with a focus on children were held in the last two years by $30 \%$ of these organizations.

Recommendations Much material has been developed to assist children, their families and schools to deal with the burden of headache disorders. Providing an indexed, downloadable inventory of these materials would allow for greater distribution, better education and higher awareness of children and the burden of their headache disorders. WHA will consider hosting the inventory on its website -by linking directly to the materials which already exist online or providing pdf files through WHA's server. Further research into the commonality of materials and cross-cultural relevance is required to define best practices.

\section{P-60} ASPIRIN FOR MIGRAINE IN CHILDREN AND ADOLESCENTS?

\section{Wöber-Bingöl}

Headache Unit, Dept. of Neuropsychiatry of Childhood and Adolescence, Medical University of Vienna, Vienna, Austria; e-mail: yasar.woeber-bingoel@univie.ac.at

Aspirin is a COX-1/COX-2 inhibitor which has been used for treating migraine attacks for more than 100 years. In adult migraineurs, several randomized controlled trials have shown that this compound is effective and safe. The combination of oral lysine acetylsalicylate and metoclopramide was as effective as oral sumatriptan in the treatment of migraine attacks. Accordingly, aspirin is widely recommended as a drug of first choice for the acute treatment of migraine attacks. In children and adolescents, only few randomized controlled studies on the treatment of migraine attacks are available. These studies examined the efficacy and safety of paracetamol/acetaminophen, ibuprofen, dihydroergotamine, sumatriptan and rizatriptan, whereas no data are available for aspirin. Recommendations for the treatment of migraine in young patients often do not mention aspirin at all or they advice against its use in general. The absence of randomized controlled trials and the advice against the use of aspirin for treating migraine attacks in children and adolescents can be explained by the risk that aspirin might cause Reye's syndrome, a potentially fatal acute central nervous system and liver dysfunction in children with certain viral infections. Pros (good efficacy in adults) and cons (risk of treating headache attributed to a viral infection) of using aspirin for migraine in children and adolescents will be discussed. 


\section{International Congress on Headache in Children and Adolescents}

\section{Author index}

A

Abu-Arafeh I, O-05
Agapejev S, P-11
Almazov I, P-25
Andrasik F, L-6, W-1, P-36, P-44, P-
51

Anttila P, P-01, P-04, P-08, P-21

Aromaa M, P-04, P-08, P-21

Arruda MA, O-01

B

Baraban D, P-40

Basgül S, P-12

Battistella P, L-16

Belopitova L, P-24, P-30, P-45

Berber M, P-29

Bojinova V, P-30, P-45

Boór K, O-03, P-16

Boranic M, P-40

Bordini CA, O-01

Buchegger H, O-16

Bugdayci R, O-09, P-02, P-05

Bussone G, P-36, P-44, P-51

C

Cady RK, O-08, P-48

Cagirici S, P-14

Capacchione G, O-15

Carrilho I, P-03

Castilho MA, P-03

Chicarella E, O-15

Chong SC, P-31

Cicconi E, P-28

Ciciarelli MC, O-01

Crenca R, P-41

\section{D}

D'Arrigo S, L-12

D'Amico D, P-36, P-44

De Colli R, P-28

De Martino P, P-15a

Djuranovic V, P-29a

Dowson A, P-46
$\mathbf{E}$

Ebinger F, P-17, P-18

Eikermann A, P-47

Eraksoy M, P-12

Erdine S, L-15

F

Farkas V, TC-7, O-03, P-16

Farmer KU, O-08, P-48

Ferrari-Ginevra O, L-12, P-26

Fiorentini N, P-28

Fisher A, O-14

Flores MA, P-49

Francis MV, O-02, O-13, P-09, P-10, P-32, P-33, P-34, P-50

Fujii Y, P-55

Fujita M, P-19

Fujiwara J, P-19

G

Galli F, TC-6, O-04, O-06, O-12, O-15

Geldner J, O-20, P-15

Gerber WD, L-9, TC-8, W-1

Giannantoni AS, O-04

Goadsby PJ, TC-1

Grazzi L, W-1, P-36, P-44, P-51

Guerra J, P-03

Guidetti V, TC-6, O-04, O-06, O-12, O-15

Gürer YK, P-13, P-27

H

Hafferl-Gattermayer A, O-20

Haller UK, W-1

Hämäläinen M, P-52, TC-4

Heinrich M, O-07, P-37

Helenius H, P-08, P-21

Hikita T, P-55

Hulihan J, O-14

Hunfeld J, P-57

\section{I}

Inan L, P-13

Iordanidis PA, W-1
Isik U, P-29

Isobe N, P-19

Izmaylova IG, P-53

$\mathbf{J}$

Jacobs D, P-47

Jäppilä E, P-21

Jegere D, P-07

Jensen RH, L-1

Jones M, P-52

Jordan D, O-14

Jun T, O-10

Just U, P-54

K

Kågedal M, P-56

Kalász H, O-03, P-16

Kaleagasi H, O-09, P-02, P-05

Kaneko S, P-55

Karakelle A, O-09, P-02, P-05

Karwautz A, O-16, O-20, P-15, P-38

Kaveh M, P-35

Kienbacher C, O-20, P-15

Kodama H, P-55

Koes B, P-57

Konrad A, O-16

Kröner-Herwig B, O-07, P-37

Kruse M, P-18

Kurt Ö, O-09, P-02, P-05

L

Laimi K, P-04

Lanzi G, L-12, P-26

Lendvai D, P-41

Leone P, P-39, P-41

Lim KJL, P-31

Lima MMF, P-11

Linder S, O-14, P-56

Lisk L, P-46, P-52

Lo Giudice R, P-15a

Lujic L, P-29a

M

Maki T, P-19 
Mandic Z, P-40

Marano GM, P-41

Marusic della Marina B, P-29a

Mazzotta G, L-16

Mejaski Bosnjak V, P-29a

Merlijn V, P-57

Metsähonkala L, L-14, P-01, P-04, P08, P-21

Montagna P, L-3

Morris L, O-07, P-37

Moscato D, L-16

\section{$\mathbf{N}$}

Nakamoto N, P-55

Neto W, P-47

Nicolodi M, O-19, P-20, P-42

\section{$\mathbf{O}$}

Oelkers-Ax R, P-54

Oksanen A, P-21

Oliveira LDB, P-11

Ölmez A, P-22, P-23

Ong HT, P-31

Orhan EK, P-12

Orosz I, O-03, P-16

Osborn J, P-41

Ostkirchen GG, P-43

Özge A, L-2, O-09, P-02, P-05

\section{$\mathbf{P}$}

Pacheva I, P-06

Padula NAMR, P-11

Parzer P, P-54

Pascotto A, O-12

Passchier J, L-10, P-57

Pearlman EM, O-14

Peracchi MI, L-16

Pinessi L, P-15a

Pirker-Binder I, W-1

Pittella S, P-41

Pothmann, L-7, P-58

Poulton R, O-11

Purina I, P-07

\section{$\mathbf{R}$}

Rating D, P-17, P-18
Rautava P, P-08

Resch F, P-54

Richardson M, P-46

Rossi LN, L-11

Rossi M, L-12, P-26

Russo PM, O-04, O-15

Ryan S, P-56

\section{$\mathbf{S}$}

Salminen JJ, P-04, P-21

Santos LCA, P-11

Sasmaz T, O-09, P-02, P-05

Sasvári-Székely M, O-03, P-16

Savi L, L-16, P-15a

Savini R, P-28

Schlotter C, P-54

Schmitt J, P-47

Schoenen J, TC-5

Schwienbacher K, O-16

Schyns T, L-4

Senbil N, P-13, P-27

Seshia SS, O-17

Shannon K, P-59

Shevel E, O-21

Shigeta M, P-19

Sicuteri F+, O-19

Sillanpää M, S-2, P-01, P-04, P-08, P21

Sinha RK, P-07

Siniatchkin M, L-9

Siva A, P-02, P-05

Smith MS, O-18

Solidei S, O-15

Soyer Ö, P-22

Soylemez D, P-14

Speciali JG, O-01

Steiner TJ, L-13

Stephani U, L-9

Stoimenova E, P-24

Symon DNK, TC-3

Szilágyi Á, O-03, P-16

\section{$\mathbf{T}$}

Taavoni S, P-35

Tagliente F, O-06, O-12

Tanfani G, O-04

Termine C, L-12, P-26
Tezcan H, P-02, P-05

Tfelt-Hansen P, S-1

Tomov V, P-24

Topçu M, P-22, P-23

Torrini A, O-19, P-20, P-42

Tozzi E, P-28

Turanli G, P-22, P-23

Turk U, P-14

Turkdogan D, P-14

$\mathbf{U}$

Ücler S, P-13

Uneri $\mathrm{O}, \mathrm{P}-12$

Usai S, P-36, P-44, P-51

V

Van der Wouden H, P-57

Verdecchia P, P-41

Viander S, P-21

Violani C, O-15

Virtanen R, P-08

W

Wagner G, O-16, P-38

Waldie KE, O-11

Wasiewski W, P-56

Webster C, P-46, P-52

Winner P, L-5, O-14, O-22, P-47, P-56

Wöber C, TC-9, L-8, O-16, O-20, P$15, \mathrm{P}-38$

Wöber-Bingöl Ç, TC-2, O-16, O-20, P-15, P-38, P-60

Y

Yalnizoglu D, P-23

Yanagawa Y, P-55

Yapici Z, P-12

Yilmaz Y, P-29

$\mathbf{Z}$

Zebenholzer K, O-20, P-15

Zesch HE, O-20

Zormann A, P-38 